\title{
IASI spectral radiance validation inter-comparisons: case study assessment from the JAIVEx field campaign
}

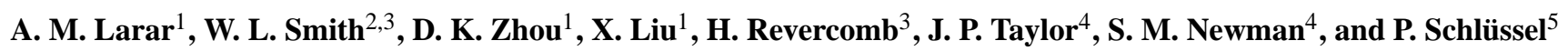 \\ ${ }^{1}$ NASA Langley Research Center, Hampton, VA, USA \\ ${ }^{2}$ Hampton University, Hampton, VA, USA \\ ${ }^{3}$ University of Wisconsin-Madison, Madison, WI, USA \\ ${ }^{4}$ Met Office, Exeter, Devon, UK \\ ${ }^{5}$ EUMETSAT, Darmstadt, Germany
}

Received: 26 February 2009 - Published in Atmos. Chem. Phys. Discuss.: 23 April 2009

Revised: 23 December 2009 - Accepted: 5 January 2010 - Published: 19 January 2010

\begin{abstract}
Advanced satellite sensors are tasked with improving global-scale measurements of the Earth's atmosphere, clouds, and surface to enable enhancements in weather prediction, climate monitoring, and environmental change detection. Measurement system validation is crucial to achieving this goal and maximizing research and operational utility of resultant data. Field campaigns employing satellite under-flights with well-calibrated Fourier Transform Spectrometer (FTS) sensors aboard highaltitude aircraft are an essential part of this validation task. The National Polar-orbiting Operational Environmental Satellite System (NPOESS) Airborne Sounder TestbedInterferometer (NAST-I) has been a fundamental contributor in this area by providing coincident high spectral and spatial resolution observations of infrared spectral radiances along with independently-retrieved geophysical products for comparison with like products from satellite sensors being validated. This manuscript focuses on validating infrared spectral radiance from the Infrared Atmospheric Sounding Interferometer (IASI) through a case study analysis using data obtained during the recent Joint Airborne IASI Validation Experiment (JAIVEx) field campaign. Emphasis is placed upon the benefits achievable from employing airborne interferometers such as the NAST-I since, in addition to IASI radiance calibration performance assessments, cross-validation with other advanced sounders such as the AQUA Atmospheric InfraRed Sounder (AIRS) is enabled.
\end{abstract}

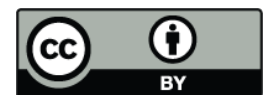

Correspondence to: A. M. Larar (allen.m.larar@nasa.gov)

\section{Introduction}

The performance of post-launch validation activities is crucial to verify the quality of satellite measurement systems. It is essential to address all components of the measurement system, i.e., sensors, algorithms, along with direct and derived data products, and continue such activities throughout program life to enable long-term monitoring of system performance for ensuring maximum research and operational utility of resultant data. Field experiment campaigns employing satellite under-flights with well-calibrated Fourier Transform Spectrometer (FTS) sensors aboard high-altitude aircraft are an essential part of this validation task. Specifically, airborne FTS systems can enable an independent, International System of Units (SI) traceable measurement system validation by directly measuring the same level-1 parameters spatially and temporally coincident with the satellite sensor of interest. Continuation of aircraft under-flights for multiple satellites during multiple field campaigns enables longterm monitoring of system performance and inter-satellite cross-validation. Data from campaign under-flights with airborne FTS systems, such as the National Polar-orbiting Operational Environmental Satellite System (NPOESS) Airborne Sounder Testbed- Interferometer (NAST-I) (Cousins et al., 1997; Smith et al., 1999), have proven to be very useful in earlier Atmospheric InfraRed Sounder (AIRS) (Aumann et al., 2003; Pagano et al., 2003) and Infrared Atmospheric Sounding Interferometer (IASI) (Amato et al., 1995; Blumstein et al., 2004; Cayla, 1993) validation studies (Larar et al., 2003, 2005, 2008; Newman et al., 2009; Tobin et al., 2006; Zhou et al., 2007a). NAST-I, maintained and deployed internationally by NASA Langley Research Center

Published by Copernicus Publications on behalf of the European Geosciences Union. 
(LaRC), serves as an ideal validation sensor since it measures the same level-1 quantity as many sensors it helps to validate (i.e. infrared spectral radiance), and does so at higher spectral and spatial resolutions. LaRC analysis is further benefited from implementing an independent set of algorithms associated with, e.g., fast radiative transfer modeling and geophysical product retrievals to enable an independent, concurrent validation of derived level-2 products (Liu et al., 2007; Zhou et al., 2007a). Field campaign data from coincident measurement assets (i.e., ground, balloon, aircraft, and satellite) are then available for not only the implementation and improvement of validation methodologies but, also, to implement, validate, and improve radiative transfer and retrieval algorithms and future measurement system specifications (e.g., Carissimo et al., 2006; Grieco et al., 2007; Strow et al., 2006, 2008; Liu et al., 2009; Serio et al., 2009; Taylor et al., 2008; Zhou et al., 2009). This manuscript focuses on validating infrared spectral radiance from the IASI instrument through a case study analysis using data obtained during the recent Joint Airborne IASI Validation Experiment (JAIVEx) field campaign. Emphasis is placed upon the benefits achievable from employing airborne interferometers such as the NAST-I for not only IASI radiance calibration performance assessment but, also, cross-validation with other advanced sounders such as the AQUA AIRS. Crossvalidation is important for referencing new observations to earlier-validated and accepted measurement assets to ensure high-quality dataset time series continuity. An overview of the JAIVEx field campaign, case study day, and instrument systems utilized for this analysis is first given. The validation methodology implemented and approach followed for assessing and inter-comparing infrared spectral radiance are then discussed. Results are then presented, followed by a summary and conclusions section. Separate papers within this IASI Special Issue publication address details of validation for derived geophysical products along with retrieval and radiative transfer models (Zhou et al., 2009; Liu et al., 2009).

\section{JAIVEx field campaign and case study day}

The JAIVEx was a United States/European collaboration focusing on validation of radiance and geophysical products from the MetOp-A (IASI/AMSU) and AQUA (AIRS/AMSU) sensors. Although all measurements on the MetOp-A and A-train satellites were of interest, the focus of JAIVEx (Smith et al., 2008) was on the validation of radiance and geophysical products from the IASI, including inter-comparisons with similar products from the AIRS. IASI, launched 19 October 2006 on MetOp-A, is the first of the advanced ultra-spectral resolution temperature, humidity, and trace gas sounding instruments to be flown on the Joint Polar System (JPS) of NPOESS and MetOp operational satellites for the purpose of improved weather, cli- mate, and air quality observation and forecasting (Chalon, 2001). The field phase of JAIVEx was conducted out of the NASA Johnson Space Center Ellington Field (EFD) in Houston, TX, between 14 April-4 May 2007. The NASA WB57 high-altitude aircraft and UK Facility for Airborne Atmospheric Measurements (FAAM) BAe146-301 aircraft (Taylor et al., 2008), well-instrumented with remote and in-situ sensors, flew coordinated sorties over the Department of Energy (DOE) Atmospheric Radiation Measurements (ARM) Cloud And Radiation Testbed (CART) site and Gulf of Mexico region during MetOp-A and A-train overpasses.

\subsection{Case study flight day}

Data from the 29 April 2007 JAIVEx flight day will be utilized for all analysis presented within this manuscript. The flight mission objective that day was to coordinate the WB-57 and BAe-146 aircraft for under-flight of the MetOp (15:50 GMT) and AQUA (19:19 GMT) satellites over the northern Gulf of Mexico. Figure 1 illustrates this flight sortie with the GOES imager scenes shown for (a) infrared, (b) visible, and (c) water vapor band extended scenes as observed by GOES (16:02 GMT), and (d) depicts the flight profile executed by the WB-57. The WB-57 flew a north-south-oriented oval racetrack pattern (at $17 \mathrm{~km}$ ) in between satellite overpass events, while the BAe-146 characterized the atmosphere and surface, from a range of altitudes below the WB-57. The WB-57 arrived on-station 20 min prior to MetOp, and remained until $10 \mathrm{~s}$ after AQUA (for a $3 \mathrm{~h}$ and $50 \mathrm{~min}$ on-station duration). Conditions ranged from very clear on the northern part of the race track, to low, puffy cumulus sparsely populating the southern extent of the flight profile, with a north-south water vapor gradient, as is shown in the GOES images of Fig. 1a-c. Figure 2 shows the sub-satellite tracks for Metop (IASI) and AQUA (AIRS) in (a) and (b), while the NASTI nadir track is shown within the IASI imager and MODIS scenes in (c) and (d), respectively.

\subsection{Instrument systems utilized in case study analysis}

Data from several different remote sensors were incorporated into this analysis; most importantly, the high spectral resolution infrared systems under direct comparison include the airborne NAST-I and Scanning High-resolution Interferometer Sounder (S-HIS) FTS systems, along with the satellitebased AIRS discrete-channel grating spectrometer, and the IASI FTS. The NAST-Interferometer, NAST-I (Cousins et al., 1997; Gazarik et al., 1998; Prutzer et al., 1998), high spectral resolution $\left(1 /[2 * \mathrm{OPD}] ; 0.25 \mathrm{~cm}^{-1}\right.$, unapodized) data are collected over the 3.7-15.5 micron spectral range, using a step and stare scanning mirror to obtain $\pm 48.4^{\circ}$ crossrange coverage with thirteen atmospheric scene views. The instrument's instantaneous field of view (IFOV) translates into a $0.13 \mathrm{~km}$ ground footprint at nadir for each $1.0 \mathrm{~km}$ of aircraft altitude (i.e. $2.2 \mathrm{~km}$ footprint from a $17 \mathrm{~km}$ WB-57 
a)

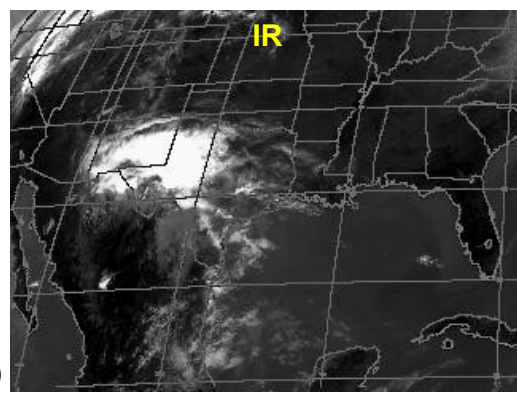

b)
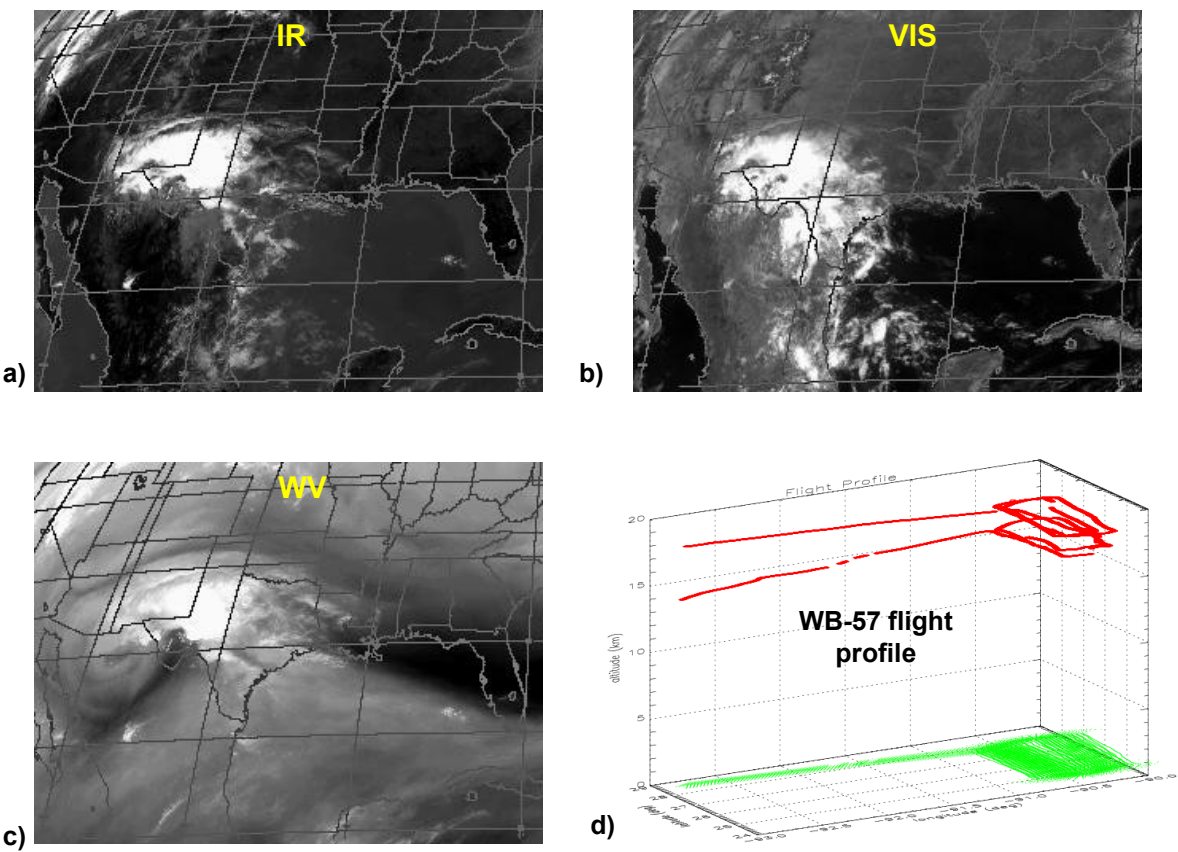

Fig. 1. JAIVEx flight mission of 29 April 2007. The extended GOES imager scenes (16:02 GMT) are shown for (a) infrared, (b) visible, and (c) water vapor bands, while the WB-57 oval racetrack flight pattern and NAST-I surface scan coverage within the north central Gulf of Mexico are shown in (d).

a)

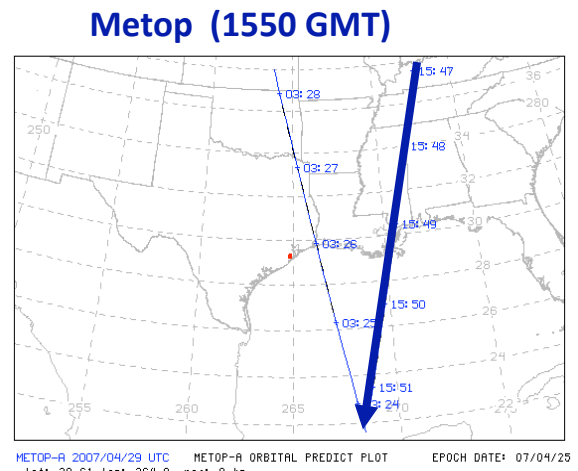

c)

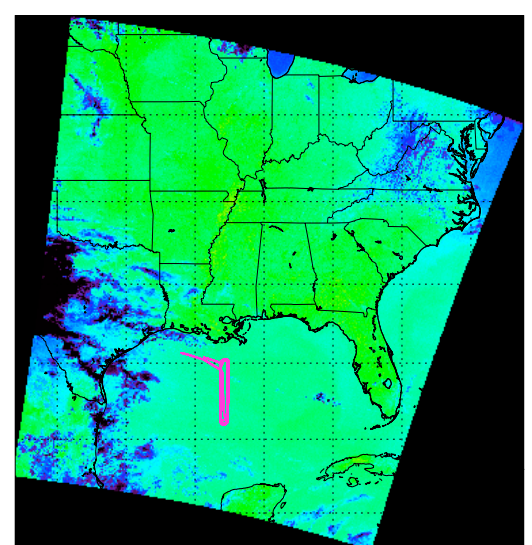

b)
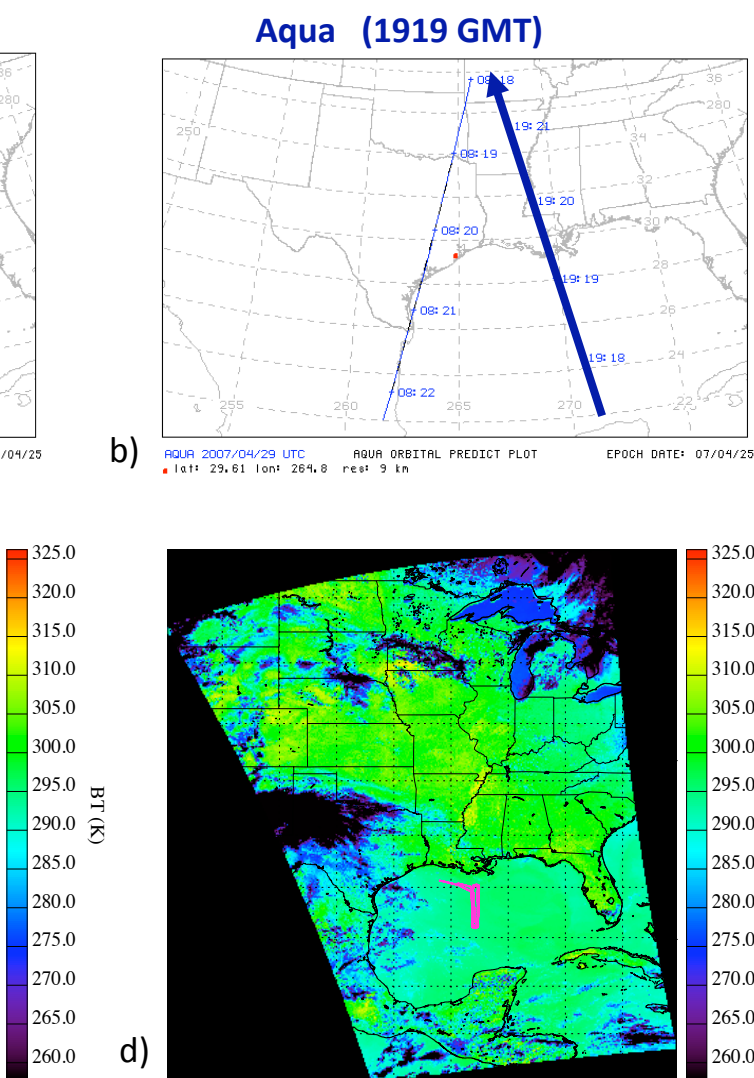

d)

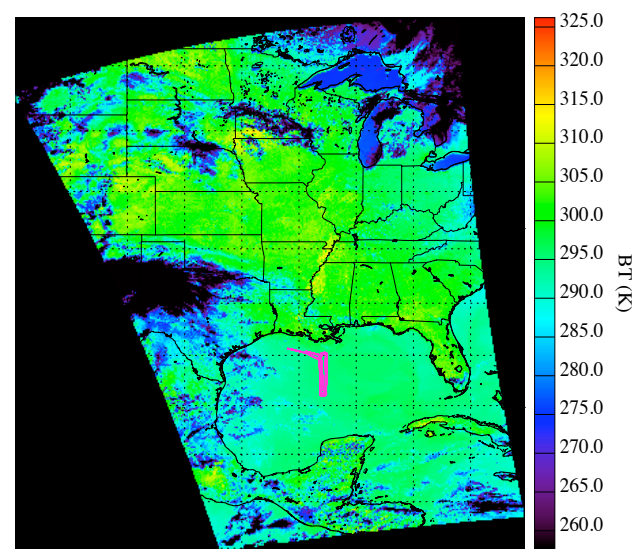

Fig. 2. JAIVEx flight mission of 29 April 2007. The sub-satellite tracks for Metop (IASI) and Aqua (AIRS) are shown in (a) and (b), while the NAST-I nadir track (pink line) is shown within the IASI imager and Modis scenes in (c) and (d), respectively. 

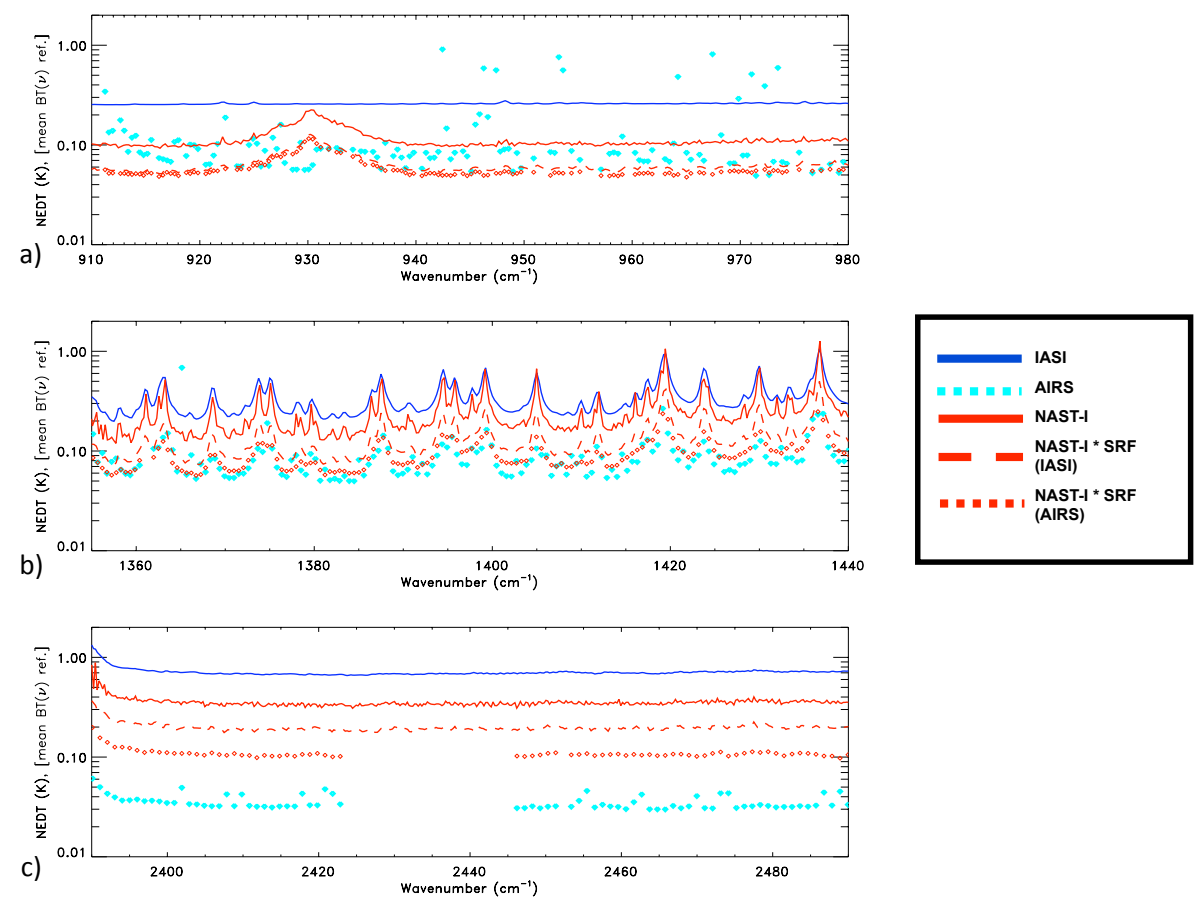

Fig. 3. Comparison of noise performance (NEDT) for AIRS, IASI, and NAST-I for the (a) longwave, (b) midwave, and (c) shortwave spectral intervals inter-compared within this study.

altitude). The S-HIS, developed and implemented by the University of Wisconsin-Madison Space Science Engineering Center (SSEC), measures emitted thermal radiation at high spectral resolution $\left(0.5 \mathrm{~cm}^{-1}\right.$, unapodized) between 3.3 and 18 microns, with $1.5 \mathrm{~km}$ resolution (at nadir) across a $30 \mathrm{~km}$ ground swath from a nominal flight altitude of $15 \mathrm{~km}$ (Revercomb et al., 1998). AIRS (Aumann et al., 2003; Pagano et al., 2003) is a high spectral resolution (resolving power, $v / \Delta v, 1200)$ grating spectrometer with 2378 bands in the thermal infrared between $3.7-15.4 \mu \mathrm{m}$ that is operational aboard the NASA EOS AQUA satellite (Chahine et al., 2006). In the cross-track direction, a \pm 49.5 degree swath centered on the nadir is scanned. Each scan line contains 90 IR footprints, with a resolution of $13.5 \mathrm{~km}$ at nadir and $41 \mathrm{~km} \times 21.4 \mathrm{~km}$ at the scan extremes from the nominal $705.3 \mathrm{~km}$ orbit. IASI is a Fourier Transform Spectrometer (Blumstein et al., 2004; Simeoni, 2007) observing the 3.7$15.5 \mu \mathrm{m}$ spectral range with a spectral resolution of $0.5 \mathrm{~cm}^{-1}$ (Gaussian apodized) utilized on the $0.25 \mathrm{~cm}^{-1}$ (unapodized spectral resolution) spectral sampling grid, while its scan mirror provides a spatial swath of \pm 48.3 degrees perpendicular to the satellite track. For each scan position, the instrument views about 3.3 degrees $\times 3.3$ degrees, or $50 \mathrm{~km} \times 50 \mathrm{~km}$ at nadir, with a $2 \times 2$ array of detectors to yield a $12 \mathrm{~km}$ nadir footprint per IFOV pixel. Broadband comparisons are also included using imager data from the MODIS sensor on AQUA and the IASI infrared imager on Metop-A. The Moderate Resolution Imaging Spectroradiometer (MODIS) is a broadband imaging sensor that provides high radiometric sensitivity in 36 spectral bands ranging in wavelength from $0.4 \mu \mathrm{m}$ to $14.4 \mu \mathrm{m}$, with a nominal band-dependent nadir resolution less than or equal to $1 \mathrm{~km}$ (Xiong and Barnes, 2006; http://modis.gsfc.nasa.gov/about/design.php). The IASI instrument includes a built-in imager, the IASI infrared imager, to enable accurate collocation between IASI and other Metop sensors as well as to provide sub-IASI-pixel cloud information. The imager covers the IASI field-of-view with $64 \times 64$ pixels providing sub-kilometer spatial resolution at nadir and has a single channel in the infrared over the 10.3 to 12.5 micron region (Blumstein et al., 2004; http://smsc.cnes. fr/IASI/GP_instrument.htm).

Figure 3 illustrates noise performance (NEDT) for the satellite systems AIRS and IASI and the airborne reference sensor NAST-I for the a) longwave, b) midwave, and c) shortwave spectral intervals inter-compared within this study. Single spectrum noise is depicted for both AIRS and IASI, whereas the NAST-I noise is reduced by a factor of SQRT(6) to reflect the average of at least 6 independent airborne spectra samples within the spacecraft sensor IFOVs. The NAST-I noise is also represented at the as-measured spectral resolution and that reduced to match IASI and AIRS, consistent with the spectral radiance plot comparisons to be shown later. This figure shows the NAST-I noise to be lower or roughly equivalent to that for IASI and AIRS for the spectral intervals being compared in subsequent figures. 


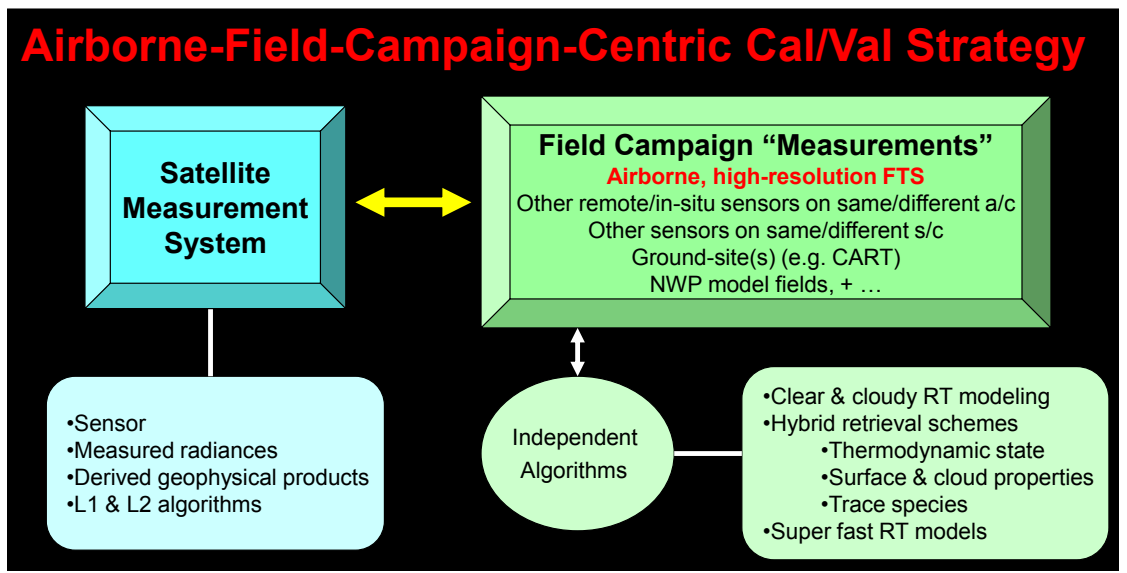

Fig. 4. Calibration/Validation strategy employed by LaRC team for the conduct of NAST-I field experiments.

The IASI instrument has absolute brightness temperature radiometric accuracy specified as better than $1 \mathrm{~K}$ with an objective of $0.5 \mathrm{~K}$, and accuracies to better than $0.25 \mathrm{~K}$ were demonstrated in pre-flight ground calibration testing (Blumstein et al., 2004). Post launch assessments (like the study herein and, e.g., Illingworth et al., 2009) are finding the IASI absolute calibration uncertainty is likely at or better than the target objective $0.5 \mathrm{~K}$ level. Pre-flight measurements and predictions for AIRS radiometric calibration accuracy were at the $0.2 \mathrm{~K}, 3$-sigma level (Pagano et al., 2008), which is consistent with post-launch inter-comparisons and analysis (e.g., Tobin et al., 2006; Shepard et al., 2008).

The S-HIS calibration techniques performed at the UW SSEC have originated from experience with several high spectral resolution interferometer programs prior to and including the S-HIS (Revercomb et al., 1988a, b, 2005). Uncertainty in the radiometric accuracy of the S-HIS data is estimated by a perturbation analysis of the radiometric calibration equation (Revercomb et al., 1988a) and also verified with independent tests using the NIST (National Institute of Science and Technology) Thermal-Infrared Transfer Radiometer (TXR). Results have shown the S-HIS absolute radiometric uncertainties to be about $0.1 \mathrm{~K}$ over much of the spectrum; specifically, for temperatures greater than $250 \mathrm{~K}$ $(235 \mathrm{~K})$, the 3 sigma total uncertainty of S-HIS radiometric calibration accuracy is reported to be less than $0.15 \mathrm{~K}(0.3 \mathrm{~K})$ (Tobin et al., 2006). NAST-I has demonstrated similar radiometric performance in ground testing at UW and NASA LaRC and through sensor inter-comparisons. And, as will be shown later in this manuscript (Fig. 9), NAST-I matches SHIS to within $0.05 \mathrm{~K}$ for the spectral regions and flight day compared within this study. This comparison serves to quantify the NAST-I radiometric calibration accuracy based upon the more extensive SI-traceable testing performed on S-HIS, and enables both a relative and absolute interpretation for the included plots illustrating spectral radiance differences from NAST-I.

\section{Validation methodology and assessment approach}

The airborne-field-campaign-centric calibration/validation (Cal/Val) strategy employed by the LaRC NAST-I team is illustrated in Fig. 4. While focused about high-resolution infrared FTS measurements (i.e., NAST-I), the strategy infuses other remote and in-situ sensors on same and different aircraft, data from other sensors on same and different spacecraft, data from ground-sites (e.g., DOE ARM CART), and geophysical model fields (e.g., Numerical Weather Prediction, NWP). NAST-I is typically flown jointly with the SHIS. This provides redundancy for the critical infrared spectral radiance measurement, helps characterize intra-platform uncertainties amongst the airborne interferometers, and enables a better linkage to reference calibration standards; as discussed in the last section, the UW SSEC has done extensive calibration testing of both NAST-I and S-HIS with blackbody sources having SI traceability to the National Institute of Standards and Technology (NIST) (Revercomb et al., 2006). Analysis is further benefited from the independent set of algorithms employed by LaRC associated with, e.g., fast radiative transfer modeling and geophysical product retrievals, to enable an independent assessment of derived level-2 products. This approach enables independent (SItraceable) measurement system validation, and enables longterm monitoring and inter-satellite cross-validation of measurement systems by underflight of multiple satellites during multiple field campaigns.

Spectral radiance validation, i.e. Cal/Val of sensor and level-1 algorithms, is a fundamental first-step prior to assessing derived geophysical parameter quality. Space and time co-location is critical for this task when the scenes being inter-compared contain significant non-uniformities. Radiosondes are frequently used for point reference comparisons and to provide statistics from the usage of large sample sizes. However, besides of radiosonde dry-bias issues at upper altitudes, they cannot provide a "coincident" 
measurement due to the ascent time (1-2h) and associated horizontal displacement (which can be $>50 \mathrm{~km}$ ). Lidar observations are much improved for accuracy and instant-time sampling, but these can only provide point measurements and still introduce forward modeling errors when producing "upwelling radiance". Airborne assets provide the only means for directly comparing radiance, providing the best match to spacecraft data, and can be implemented anywhere unlike fixed ground sites.

The objective of the analysis herein is to infuse multiple spatially- and temporally-coincident data sources from several independent sensors and simulations for enabling intercomparison and assessment of high-resolution infrared spectral radiance measurements from IASI and the other coincident sensors. Simulated observations are based upon lineby-line (LBL)-based radiative transfer model (LBLRTM) (Clough et al., 2005; Shephard et al., 2009) calculations using the most recent code (i.e., Version 11.3) and best available estimate of surface and atmospheric state. Airborne FTS sensors, such as the NAST-I, serve as ideal validation sensors due to their higher spatial and spectral resolution (samescene) measurements which can then be degraded to best emulate that observed by the coincident satellite sensors.

\subsection{Analysis approach}

The goal of this case study is to assess IASI spectral radiances standalone and relative to AIRS. Methods employed herein to address this include comparisons of measured IASI radiances with simulations and other measurements. Simulations presented use the best available estimate for atmospheric state (from, e.g., NWP model fields, radiosondes, or independent retrievals). Other measurements used in the comparisons fit within two basic categories: those on the same platform (i.e., intra-platform) and comparison of measurements from different platforms (i.e., inter-platform). Since the airborne interferometer measurements provide the best characterization of scene evolution (as will be shown in the Inter-comparison Results section of this manuscript) these data will also be used as a calibration reference standard to remove scene evolution for a more-representative IASI versus AIRS comparison. This approach can be summarized as follows:

1. Comparisons with simulations. Spectral radiances from select IASI IFOVs are first compared with line-by-line radiative transfer model simulations using estimates of atmospheric state derived from NWP model fields (i.e. European Center for Medium-range Weather Forecasting, ECMWF, Gibson et al., 1997), local radiosonde observations, and independently-derived retrievals (Zhou et al., 2002, 2005, 2007b).

2. Intra-platform comparisons. Radiance measurements from each available platform are compared with consistent measurements from the same platform. This consists of comparing the following spectrally- and spatially-consistent observations: IASI versus IASI imager (on MetOP-A), AIRS versus MODIS (on AQUA), and NAST-I versus S-HIS (on WB-57). This enables a platform self-consistency verification while having large sample size comparisons with negligible collocation and viewing geometry errors (i.e., temporal, spatial, angular, and platform altitude).

3. Inter-platform comparisons. High spectral resolution radiance measurements are compared with like observations from a different platform. This enables comparing new sensors, such as IASI, to known, previously-validated assets (such as NAST-I, S-HIS, and AIRS). For scene observations that are not temporally-coincident, a reference calibration standard is desirable to account for scene evolution. The following inter-platform comparisons are included:

a) Direct IASI vs. AIRS comparisons. As a first-order comparison, spatially-coincident latitudinal cross-sections from IASI are compared with similar observations from AIRS.

b) Aircraft vs. spacecraft. NAST-I spectral radiances are compared with spatially- and temporally-coincident observations from both IASI and AIRS.

c) Indirect IASI vs. AIRS comparisons. Since NAST-I observes the scene evolution between the Metop-A and AQUA overpasses during the case study JAIVEx flight day, these observations are used as a calibration reference standard to remove scene evolution and enable indirect cross-validation comparisons between IASI and AIRS.

\section{Inter-comparison results}

Spectral radiance inter-comparison is a fundamental firststep prior to assessing derived geophysical parameter quality. As detailed in the last section, the goal of this case study is to assess IASI spectral radiances standalone and relative to AIRS through comparisons of measured IASI radiances with simulations and other measurements selected from the JAIVEx case study day. The figures shown in this section illustrate some example infrared spectral radiance validation results. The inter-comparison results are presented as outlined in the comparison approach detailed within the last section of this manuscript.

1. Comparisons with simulations. Figure 5 shows example simulations for an IASI measured spectrum of a select IFOV within the case study day Metop-A overpass. Figure 5a illustrates the selected IFOV relative to the subsatellite track, which is an arbitrarily-selected radiosonde location (i.e., FFC, near Atlanta, GA). Figure 5b shows 
a)
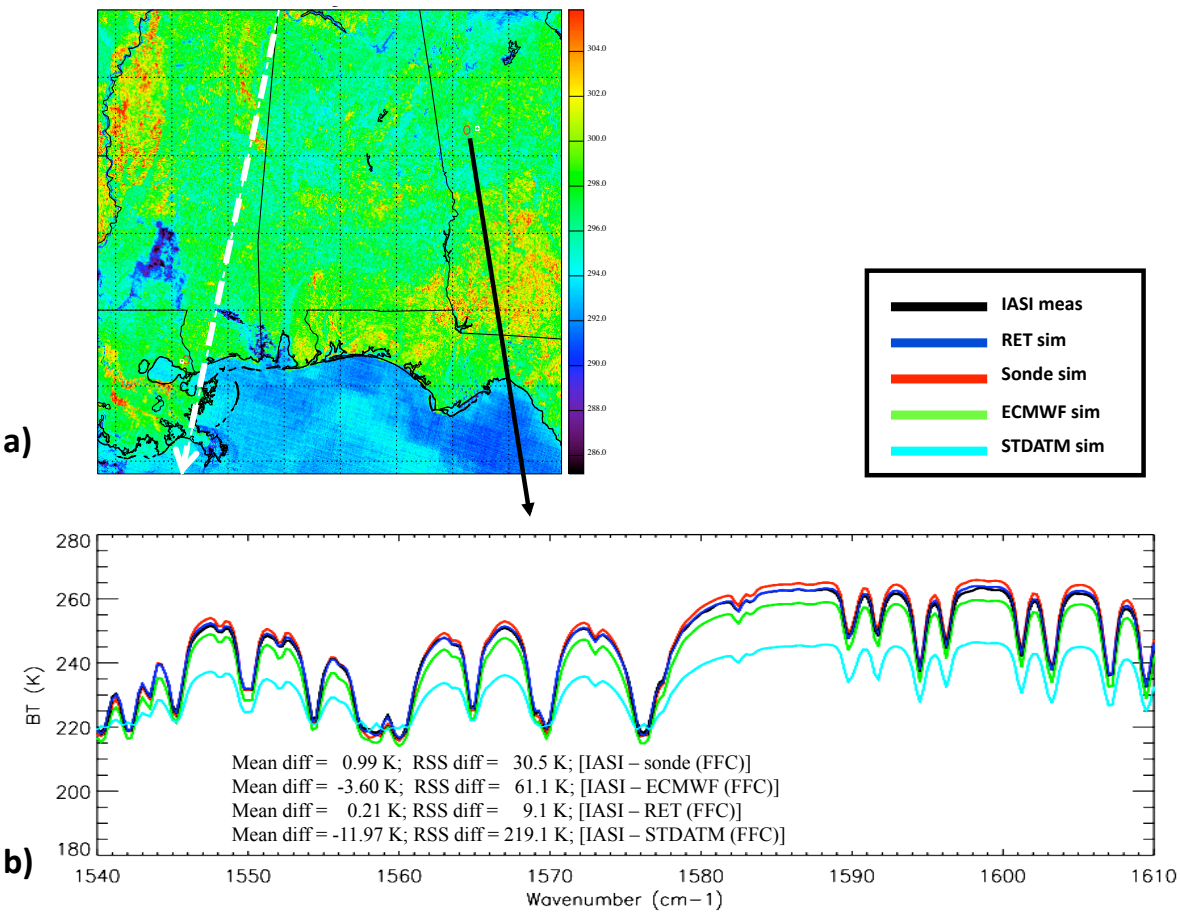

Fig. 5. IASI measured spectrum versus simulation for a select IFOV on the 29 April 2007 JAIVEx region overpass at 15:50 GMT. Selected IFOV position shown within the IASI imager scene data in (a) along with the sub-satellite track (white-dashed arrow).

the IASI measured spectrum along with four simulation results using different estimates to represent the atmospheric state. Specifically, in order of increasing ability to match this specific IASI measurement, simulations utilize the 1976 Standard Atmosphere (Krueger and Minzner, 1976) $(-12 \mathrm{~K})$, ECMWF $(-3.6 \mathrm{~K})$, radiosonde $(0.99 \mathrm{~K})$, and an independent IASI retrieval $(0.21 \mathrm{~K})$; the parenthetical values represent the mean (IASI-simulation) differences across the $1540-1610 \mathrm{~cm}^{-1}$ spectral region shown. The relative goodness of these simulations is in the expected order, i.e. they get better as one goes from models to measurements of closer space and time coincidence. It is interesting to point out that while the retrieved atmospheric state was produced from this specific IASI spectrum, it does not yield perfect results in this comparison since an independent atmospheric stratification and radiative transfer model have been implemented; this example is included to illustrate the point that even assuming a perfectly-known atmospheric state, the forward model errors can still be on the order of a couple tenths of a degree $\mathrm{K}$. This figure serves to demonstrate that results from simulations alone are not close enough for advanced sounder validation since they are limited by knowledge of atmospheric state, surface characteristics, spectroscopy, and other forward modeling parameters. Regardless, however, simulations must play a vital role in the spacecraft sensor validation process since they increase the sampling statistics, allow covering larger spatial and temporal scales, and enable accounting for radiance contributions associated with scene view differences, unlike that possible with other measurement-only comparison approaches.

2. Intra-platform comparisons. Intra-platform comparisons for IASI and AIRS are limited to comparisons with broadband imagers having lower requirements for radiometric and spectral resolutions and calibration. While this limits their ability to validate spectral radiance stand-alone, they are certainly very important components to and of value for validation. Figure 6 illustrates a comparison of IASI versus the IASI imager for the JAIVEx flight region scene. Figure 6a shows the imager data degraded to IASI spatial resolution over the IASI scene region while Fig. $6 \mathrm{~b}$ has IASI spectrally degraded through application of the IASI imager spectral response function, making the comparison of Fig. 6a to b spatially- and spectrally-consistent. Figure 6c uses a histogram to depict the differences between the scenes in Fig. 6a-b. The mode of this distribution is $0.23 \mathrm{~K}$, which is quite close considering the uncertainties involved in this comparison. The outliers in this distribution are mainly due to heterogeneous regions of the scene (e.g. clouds) which are most sensitive to spatial errors in the IFOV matchups between IASI and the IASI imager. Figure 7 shows the same type of comparison as in Fig. 6 but represents AIRS versus MODIS band 31 (MB31, 11 micron window region) for the JAIVEx flight region scene. Figure 7a shows the MODIS data degraded to AIRS spatial resolution over the AIRS scene region while Fig. 7b has AIRS spectrally 
a)

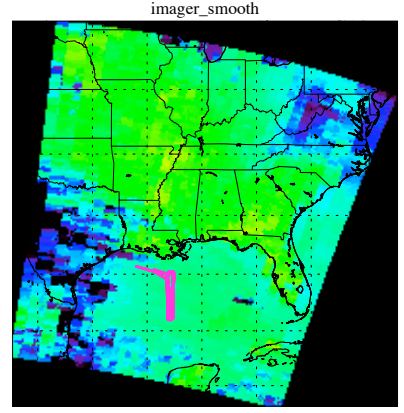

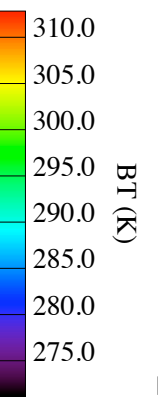
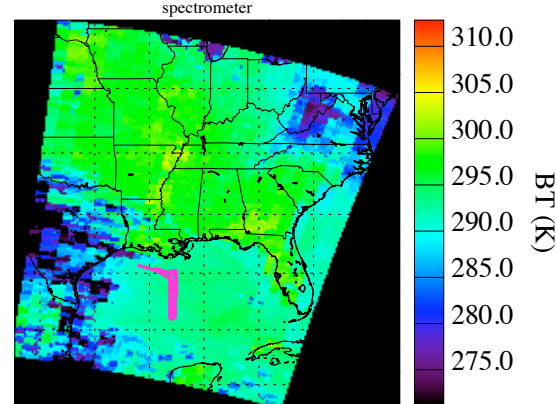

c)

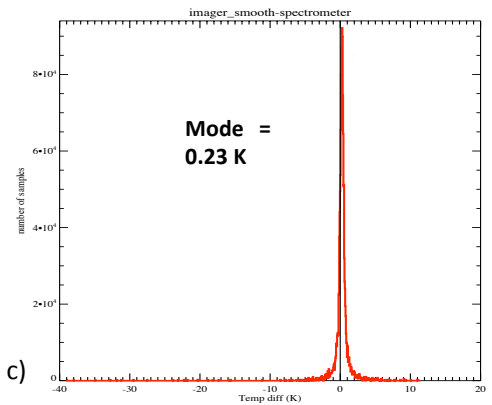

Fig. 6. IASI versus IASI imager for the Metop-A scene over the 29 April 2007 JAIVEx flight mission: (a) imager degraded to IASI spatial resolution over IASI scene, (b) IASI spectrally degraded through application of IASI imager spectral response function, and (c) histogram of scene (a) - scene (b).

a)

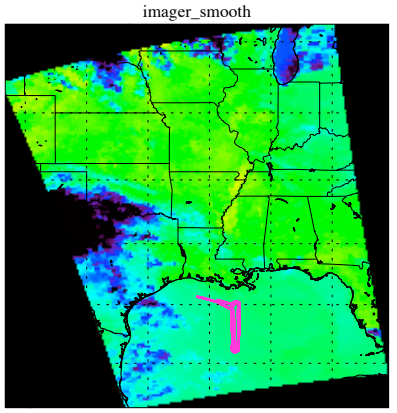

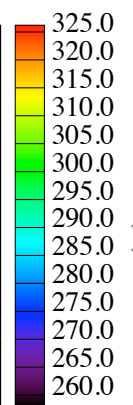

b)

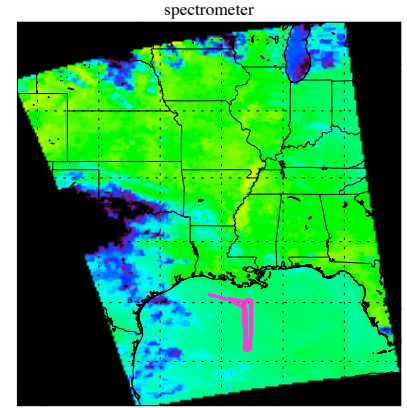

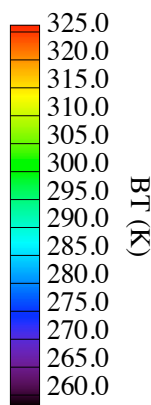

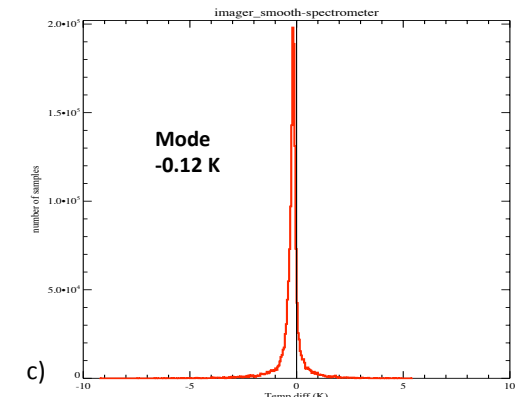

Fig. 7. AIRS versus Modis Band 31 (MB31) for the Aqua scene over the 29 April 2007 JAIVEx flight mission: (a) MB31 degraded to AIRS spatial resolution over AIRS scene, (b) AIRS spectrally degraded through application of MB31 spectral response function, and (c) histogram of scene (a) - scene (b). 

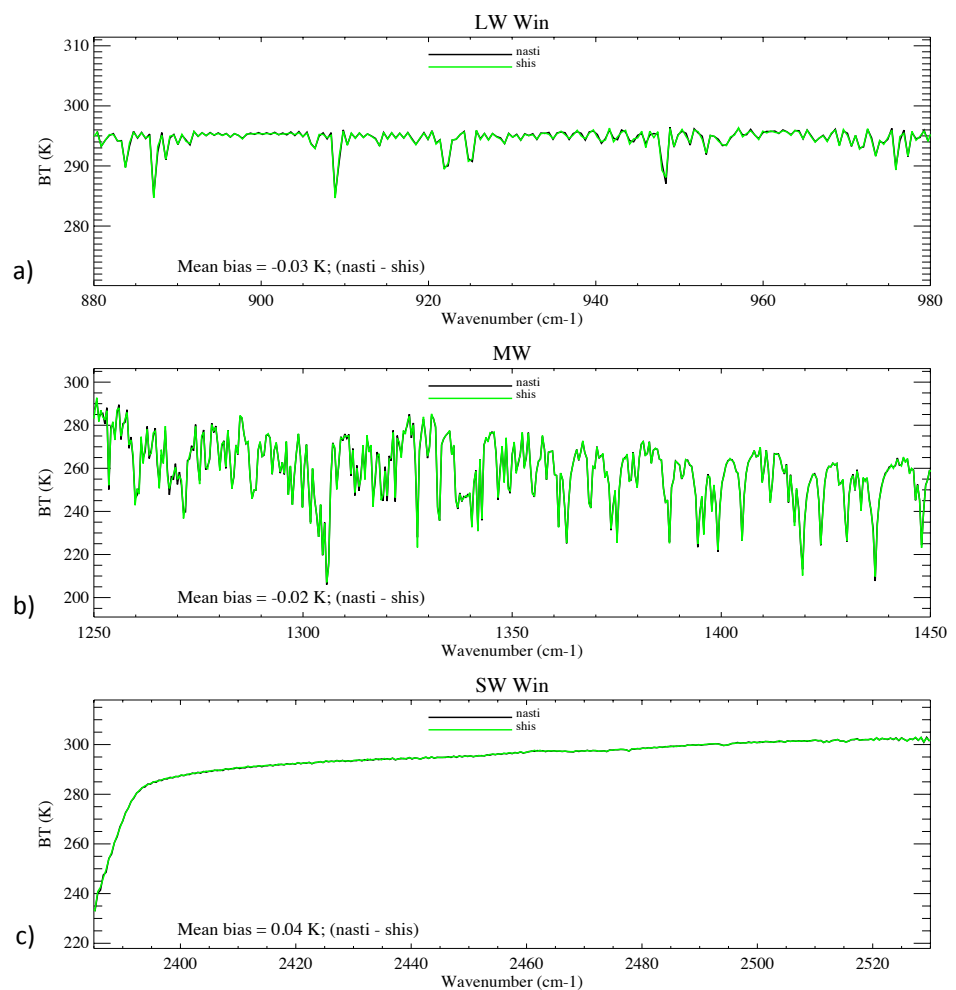

Fig. 8. Average NAST-I versus S-HIS spectra for collocated scenes during the 29 April 2007 JAIVEx flight mission, for the (a) longwave window $\left(880-980 \mathrm{~cm}^{-1}\right)$, (b) midwave $\left(1250-1450 \mathrm{~cm}^{-1}\right)$, and (c) shortwave window $\left(2385-2530 \mathrm{~cm}^{-1}\right)$ spectral regions. Note that the higher-resolution NAST-I data have been reduced to the S-HIS spectral resolution.

degraded through application of the MB31 spectral response function, making the comparison of Fig. 7a to b spatiallyand spectrally-consistent. Figure $7 \mathrm{c}$ uses a histogram to depict the differences between the scenes in Fig. 7a-b. The mode of this distribution is $-0.12 \mathrm{~K}$ which, as in the last example, is quite close considering the uncertainties involved in this type of comparison.

Intra-platform comparison among the WB-57 airborne sensors enables comparison of the high spectral resolution interferometer instruments NAST-I and S-HIS. Figure 8 shows a comparison of NAST-I versus S-HIS for average spectra from collocated scenes during the 29 April 2007 JAIVEx flight mission for the (a) longwave window (880-980 $\left.\mathrm{cm}^{-1}\right)$, (b) midwave $\left(1250-1450 \mathrm{~cm}^{-1}\right)$, and (c) shortwave window $\left(2385-2530 \mathrm{~cm}^{-1}\right)$ spectral regions. Mean differences of these spectra are shown to be $-0.03 \mathrm{~K}$, $-0.02 \mathrm{~K}$, and $0.04 \mathrm{~K}$ for these spectral regions, respectively. The higher-resolution NAST-I data have been reduced to the S-HIS spectral resolution for a spectrally-consistent comparison. Figure 9 shows a scatter plot of NAST-I versus $\mathrm{S}$-HIS for the average spectra shown in Fig. 8. A $10 \mathrm{~cm}^{-1}$ boxcar smoothing has first been applied to the spectra to better facilitate radiometric calibration inter-comparison. As indicated in the figure, the $800-1010 \mathrm{~cm}^{-1}, 1215-$ $1615 \mathrm{~cm}^{-1}$, and $2385-2600 \mathrm{~cm}^{-1}$ spectral regions have been included and show mean differences on the order of hundredths of a degree $\mathrm{K}$; this provides a consistency check of NAST-I relative to S-HIS for larger spectral extents than are used in later examples comparing NAST-I to IASI and AIRS.

\section{Inter-platform comparisons.}

a) Direct IASI vs. AIRS comparisons. Figure 10 shows nadir and common cross-section lines extracted in the next example for a first-order direct comparison of IASI and AIRS, and extend \pm 5 degrees in latitude from the sub-satellite intersection point of the satellite ground tracks for a) IASI and b) AIRS. Tracks are shown on top of platform imager scenes, i.e., IASI imager and MODIS (MB31), respectively. Figure 11 shows water vapor band (1540-1610 $\mathrm{cm}^{-1}$ ) latitudinal cross-sections (deviation from brightness temperature mean, $\mathrm{K}$ ) along the sub-satellite nadir for a) IASI, b) AIRS, and along a common cross-section for c) IASI and d) AIRS. The nadir cross-sections have a point-in-space coincidence, and the common cross-sections have a line-in-space coincidence; however, temporal coincidence is shown to be more important since the different cross-sections from each sensor seem to more resemble each other than the corresponding cross-sections from the other sensor (that are not temporally coincident). The importance of time coincidence in comparisons involving an evolving 


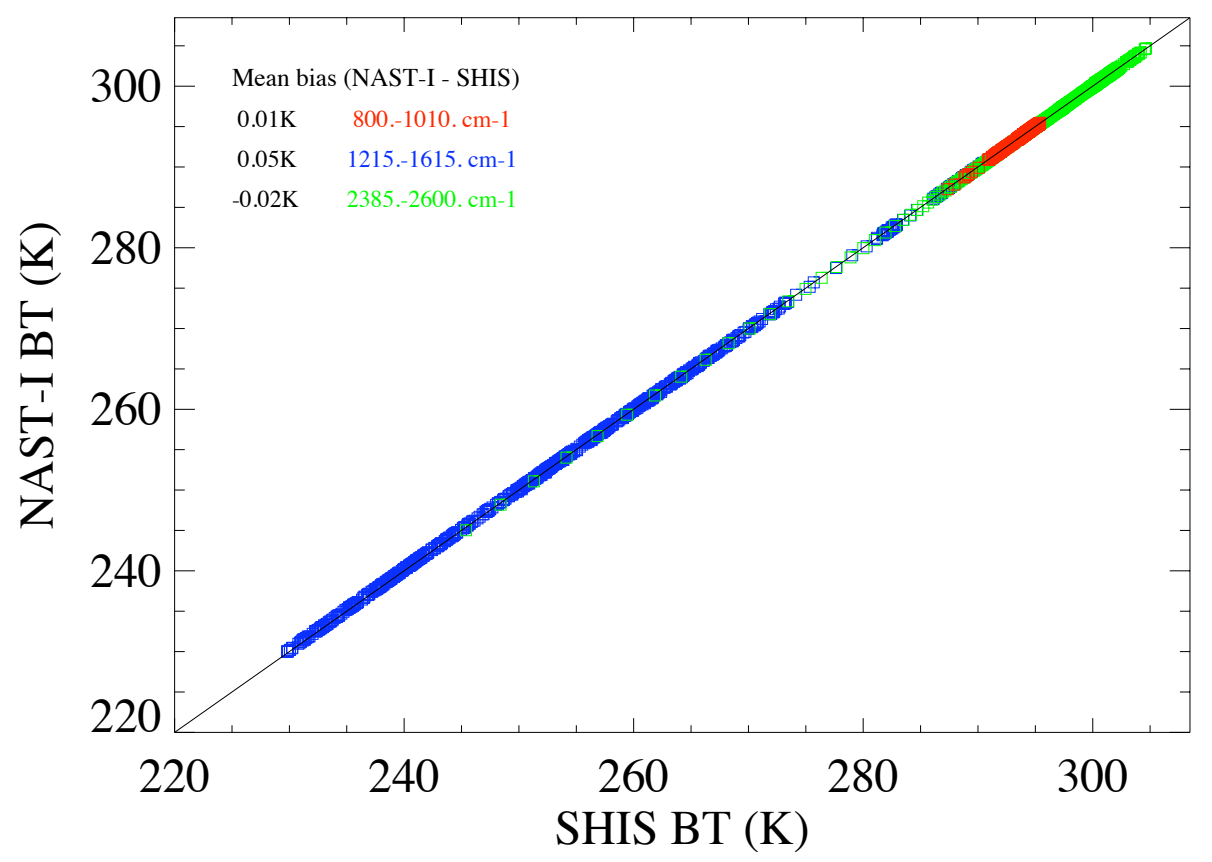

Fig. 9. Scatter plot of NAST-I versus S-HIS for average spectra shown in Fig. 7. The higher-resolution NAST-I data have been reduced to the S-HIS spectral resolution and spectra have been smoothed over $10 \mathrm{~cm}^{-1}$ to better facilitate radiometric calibration inter-comparison. As indicated in the Figure, the $800-1010,1215-1615$, and $2385-2600 \mathrm{~cm}^{-1}$ spectral regions are shown.

a)
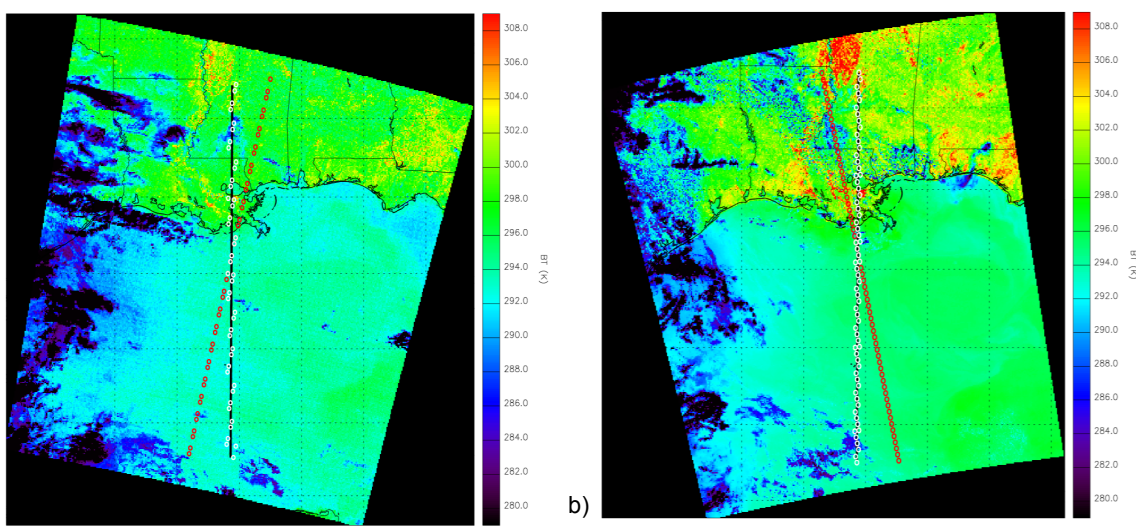

Fig. 10. Nadir and common cross-section lines extracted for first-order direct comparison of IASI and AIRS, \pm 5 degrees latitude from subsatellite intersection point of the satellite ground tracks for (a) IASI and (b) AIRS. Tracks are shown on top of platform imager scenes, i.e., IASI imager and Modis B31, respectively. 

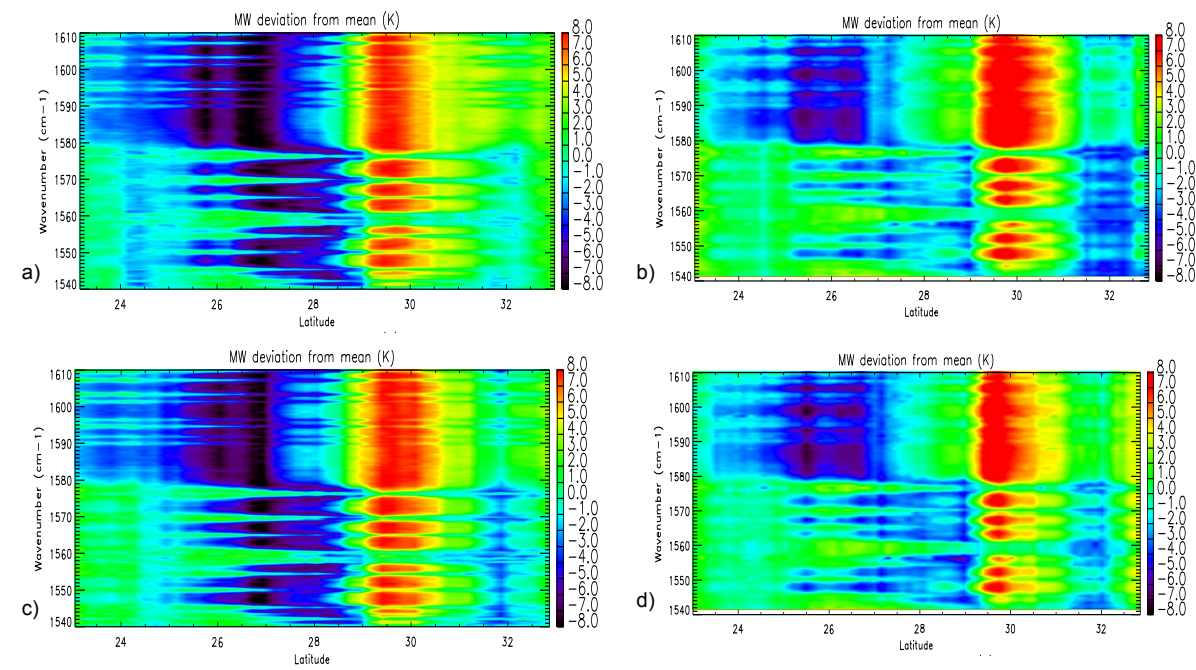

Fig. 11. Water vapor band (1540-1610 $\mathrm{cm}^{-1}$ ) latitudinal cross-sections (deviation from mean, K) along sub-satellite nadir for (a) IASI, (b) AIRS, and along a common cross-section for (c) IASI and (d) AIRS. Nadir cross-sections have point-in-space coincidence while common cross-sections have line-in-space coincidence.
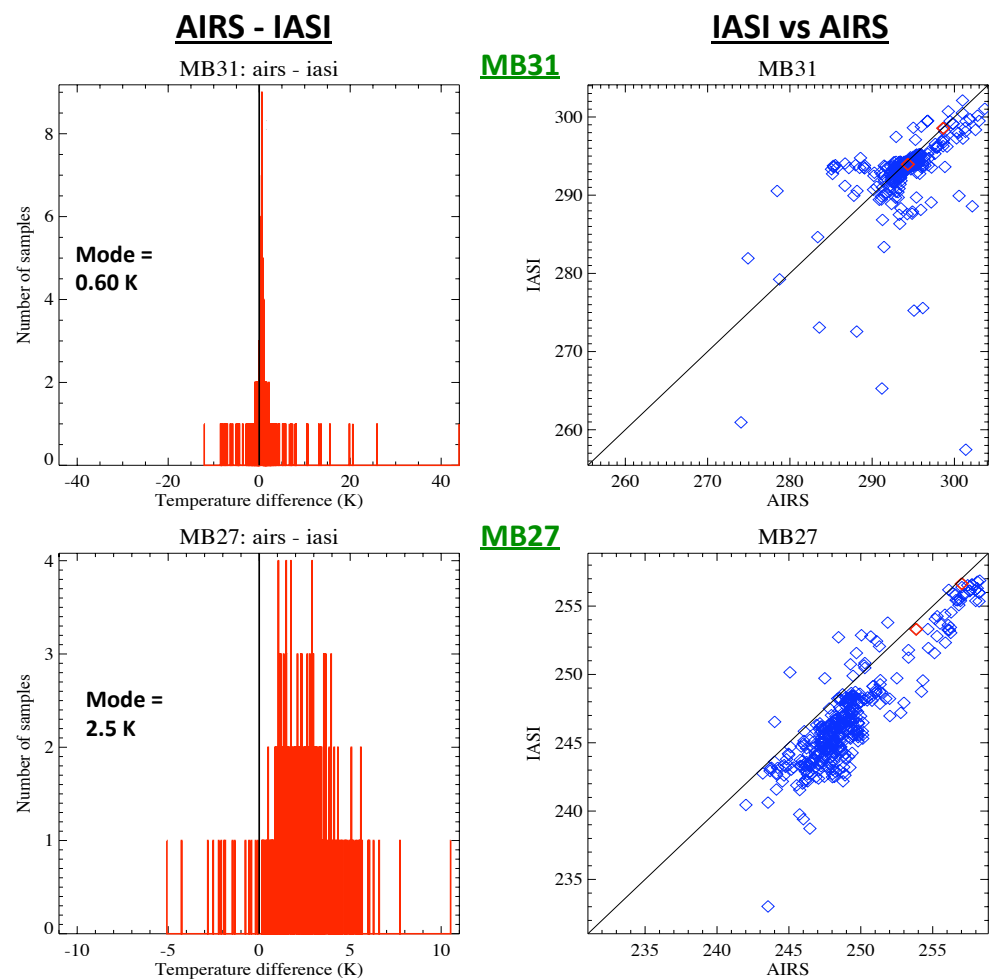

Fig. 12. Direct comparison of IASI and AIRS coincident IFOVs within the JAIVEx 29 April 2007 flight domain. Select Modis spectral response functions have been applied (to the IASI and AIRS spectral radiances) to illustrate scene evolution (between satellite overpasses) from a broadband difference perspective. Longwave window (MB31) and midwave water vapor (MB27) regions are shown in the top and bottom plots, respectively. 

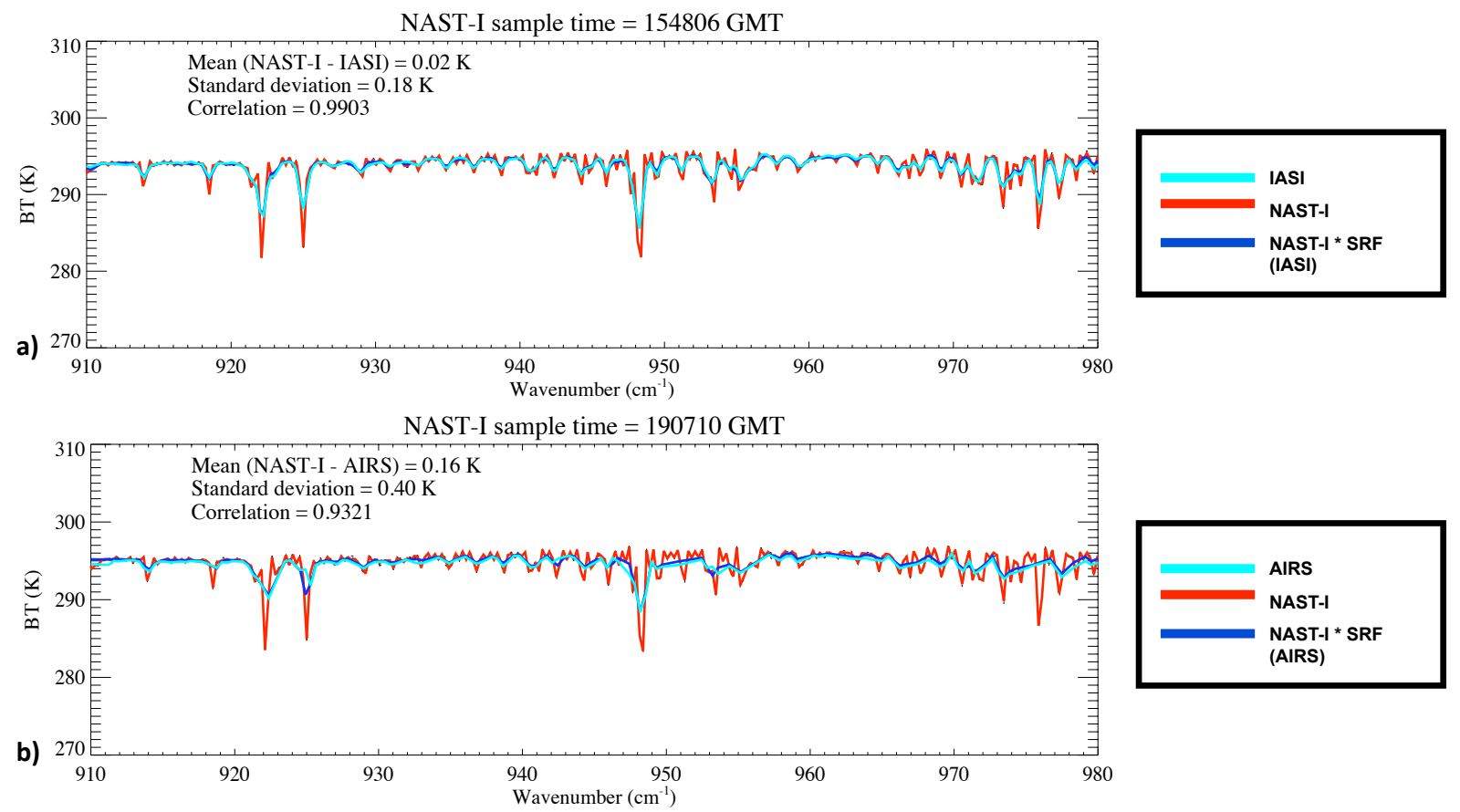

Fig. 13. Example infrared spectral radiance inter-comparisons for the longwave window $910-980 \mathrm{~cm}^{-1}$ (11.0-10.2 micron) spectral region showing space and time coincident NAST-I relative to (a) IASI and (b) AIRS measurements.

geophysical field is also illustrated in the next example. Figure 12 shows another direct comparison of IASI and AIRS coincident IFOVs within the JAIVEx 29 April 2007 flight domain. Select MODIS spectral response functions have been applied to illustrate scene evolution (between satellite overpasses) from a broadband perspective. Longwave window (MB31) and midwave water vapor (MB27) regions are shown in the top and bottom plots, respectively. The goal was to find IFOVs with a minimum of scene evolution since any direct comparison of instruments will include both instrument differences and scene changes. In this example, out of the 374 IFOVs that overlap spatially in the JAIVEx "study region" only 2 can be found to satisfy a close match; i.e. $\sim 0.5 \%$ of the scenes produce a difference of $\sim 0.75 \mathrm{~K}$, band averaged, which is still larger than desired for validation. The last two examples illustrate that, unlike the simultaneous nadir observation (SNO) comparisons possible in polar regions (see, e.g., Cao et al., 2005), such direct satellite-to-satellite comparisons in lower latitude regions (where significant time can exist between overpasses) can contain significant scene evolution differences making them difficult to utilize for detecting small instrument differences in $\mathrm{Cal} / \mathrm{Val}$.

b) Aircraft vs. spacecraft. Space and time collocation is critical for the validation task when the scenes being inter-compared contain significant non-uniformity in the spatial and temporal domains, respectively. Airborne FTS assets, such as the NAST-I and S-HIS, are uniquely able to provide such collocation and enable the best overall direct radiance inter-comparisons. The comparisons shown in this section are all for single spacecraft sensor IFOVs relative to combined near-nadir NAST-I observations coincident in space and time. Since NAST-I is of higher spectral resolution than the spacecraft sensors, an additional curve (in blue) is added in the plots to enable same-spectral resolution comparisons. The spectral regions selected for comparing aircraft versus spacecraft measurements within this study are limited to those having insignificant absorption/emission above the aircraft altitude (i.e. water vapor band and window regions), since inclusion of other spectral regions would introduce additional comparison uncertainty (i.e. beyond simply sensor measurement errors being addressed herein) via the subsequently needed radiative transfer modeling component to account for atmospheric contributions between these platforms. Figure 13 shows example infrared spectral radiance inter-comparisons for a longwave window (910-980 $\mathrm{cm}^{-1}$ ) spectral interval between select space and time coincident NAST-I observations relative to a) IASI and b) AIRS measurements. Mean differences over this spectral interval are shown to be $0.02 \mathrm{~K}$ and $0.16 \mathrm{~K}$ for (NAST-I - IASI) and (NAST-I - AIRS), respectively. A similar comparison for a midwave (1355-1440 $\mathrm{cm}^{-1}$ ) spectral interval is shown in Fig. 14. This example uses different IFOVs to show comparisons to such levels are not outlier occurrences and, as with the last example, space and time 

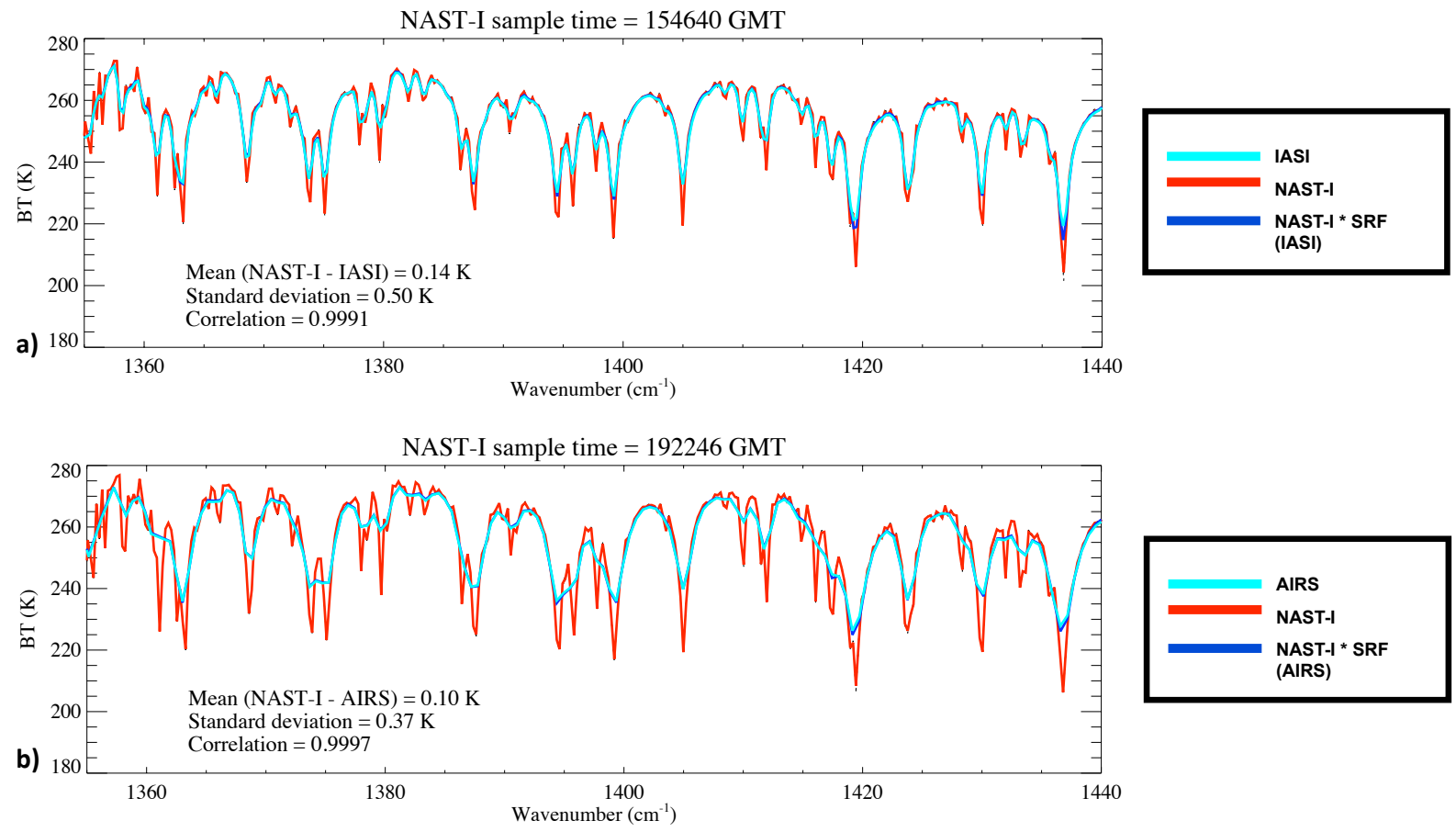

Fig. 14. Example infrared spectral radiance inter-comparisons for the water vapor $1355-1440 \mathrm{~cm}^{-1}(7.4-6.9$ micron) spectral region showing space and time coincident NAST-I relative to (a) IASI and (b) AIRS measurements.
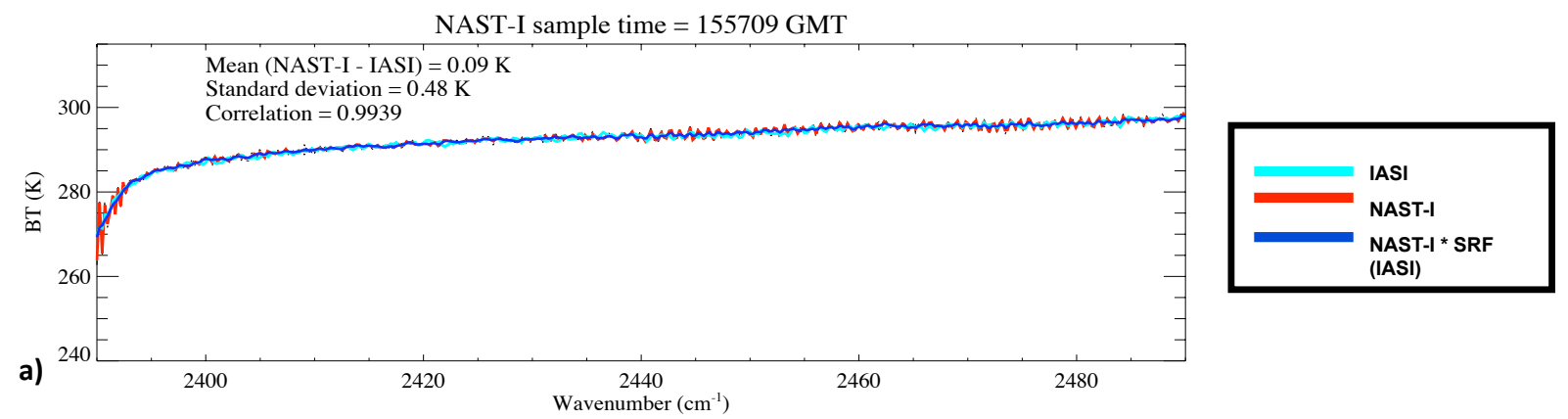

NAST-I sample time $=185020$ GMT
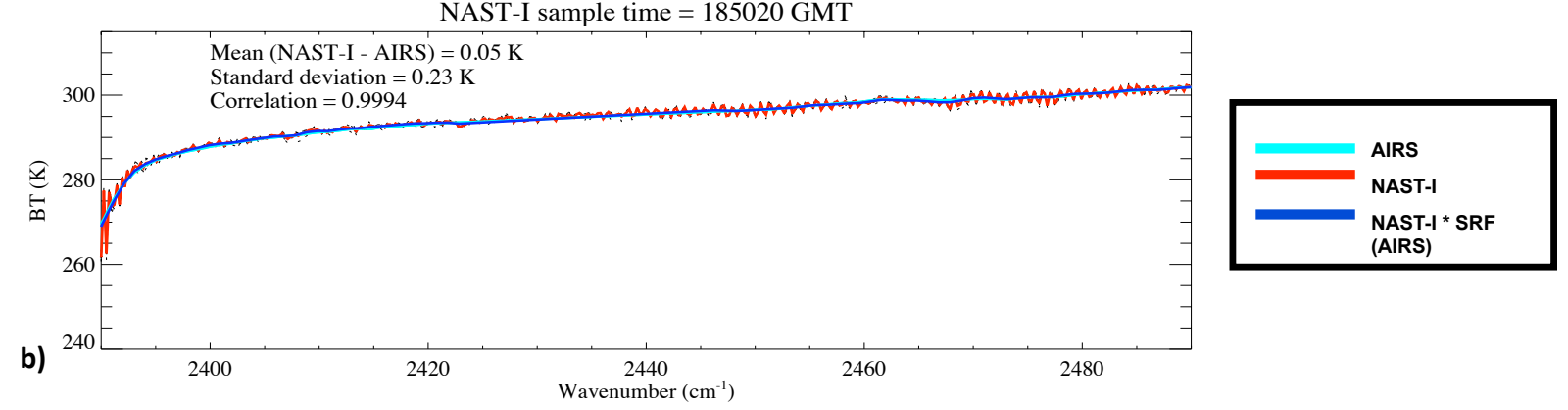

Fig. 15. Example infrared spectral radiance inter-comparisons for the shortwave window $2390-2490 \mathrm{~cm}^{-1}(4.2-4.0 \mathrm{micron}) \mathrm{spectral} \mathrm{region}$ showing space and time coincident NAST-I relative to (a) IASI and (b) AIRS measurements. 

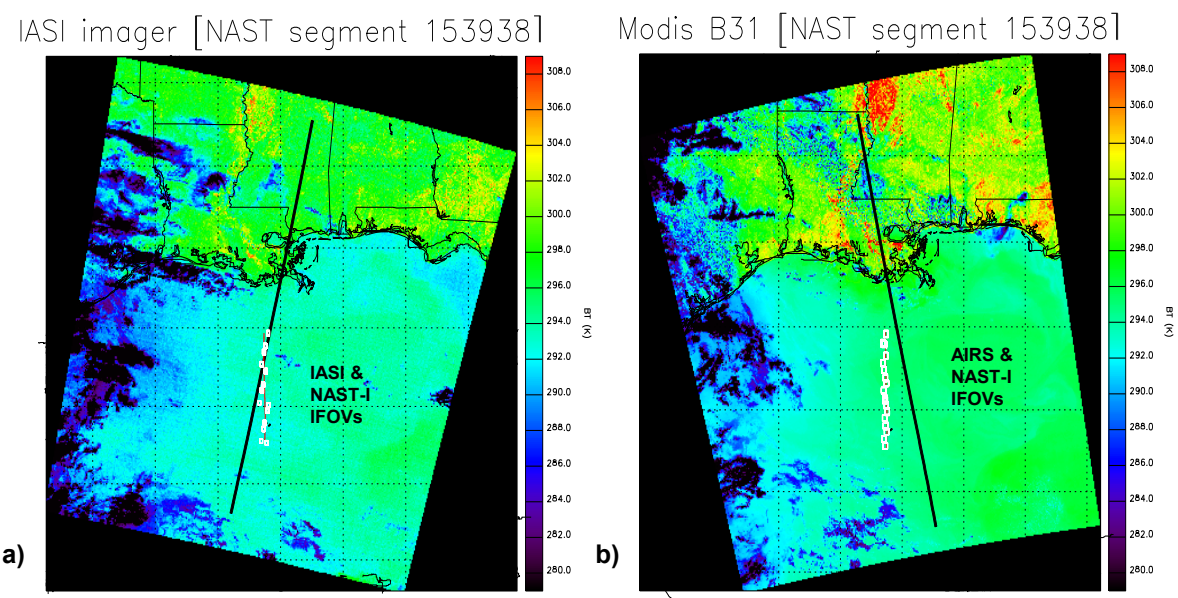

Fig. 16. Select NAST-I nadir tracks relative to sub-satellite tracks for (a) IASI and (b) AIRS.
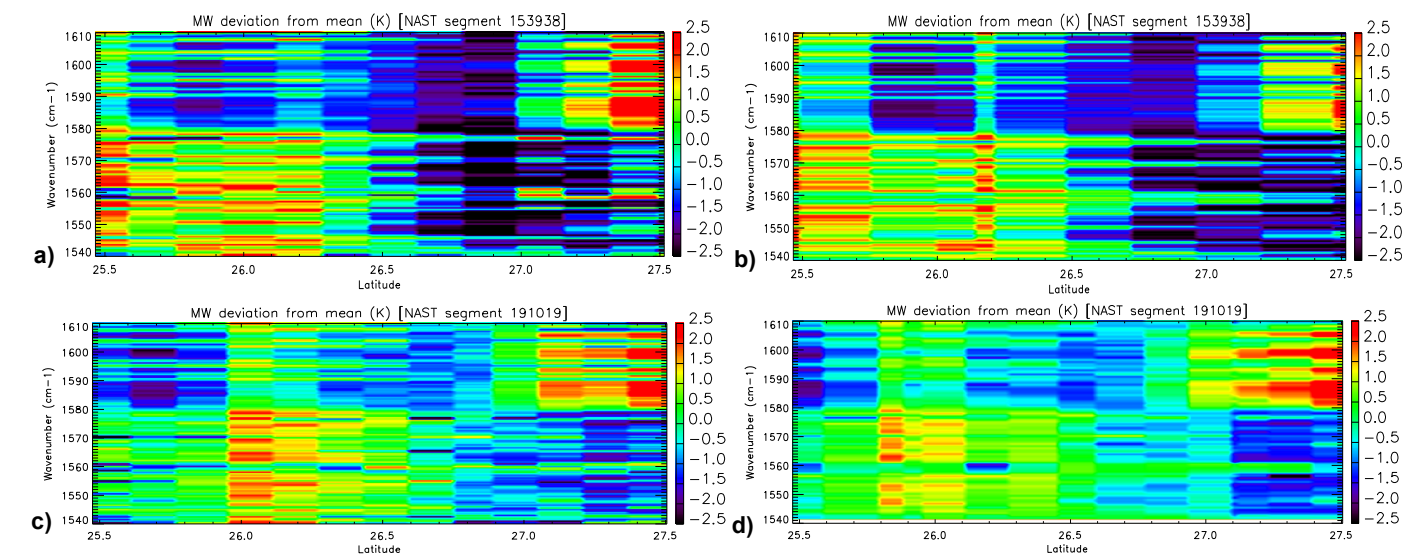

Fig. 17. Water vapor band $\left(1540-1610 \mathrm{~cm}^{-1}\right)$ spectral radiance latitudinal cross-sections for (a) NAST-I at the IASI overpass time, (b) IASI, (c) NAST-I at the AIRS overpass time, and (d) AIRS.

coincident NAST-I observations are shown relative to a) IASI and b) AIRS measurements. Mean differences over this spectral interval are shown to be $0.14 \mathrm{~K}$ and $0.10 \mathrm{~K}$ for (NAST-I - IASI) and (NAST-I - AIRS), respectively. The shortwave window region is also included with a comparison of the 2390-2490 $\mathrm{cm}^{-1}$ spectral interval shown in Fig. 15. Once again, different space and time coincident IFOVs have been selected to compare NAST-I observations relative to a) IASI and b) AIRS measurements. Mean differences over this spectral interval are shown to be $0.09 \mathrm{~K}$ and $0.05 \mathrm{~K}$ for (NAST-I - IASI) and (NAST-I - AIRS), respectively. The airborne FTS versus spacecraft sensor comparisons included in this section show IASI and AIRS spectral radiances both matching coincident NAST-I observations to within $\sim 0.1 \mathrm{~K}$ (band-averaged). Such inter-comparisons yield the closest levels of direct radiance comparisons and verification to these levels is hard to achieve using other approaches. c) Indirect IASI vs. AIRS comparisons. The remaining figures in this section are focused on enabling an indirect radiometric comparison of IASI and AIRS utilizing NAST-I observations, covering the time in between Metop-A (IASI) and AQUA (AIRS) overpasses, to remove differences due to scene evolution. Figure 16 illustrates the sampling logistics for the next example, showing select NAST-I nadir tracks relative to sub-satellite tracks for a) IASI and b) AIRS which are used for data cross-section extraction. Figure 17 shows water vapor band $\left(1540-1610 \mathrm{~cm}^{-1}\right)$ spectral radiance latitudinal cross-sections for a) NAST-I at the IASI over pass time, b) IASI, c) NAST-I at the AIRS overpass time, and d) AIRS. Note that the NAST-I observations are degraded both spectrally and spatially to more-appropriately compare with IASI and AIRS in this example. As can be seen in this figure, space and time coincident NAST-I provides a better match to IASI observations than space-only coincident AIRS (i.e., a best matches b), and to AIRS observations than space-only coincident IASI (i.e., c best matches d), further 


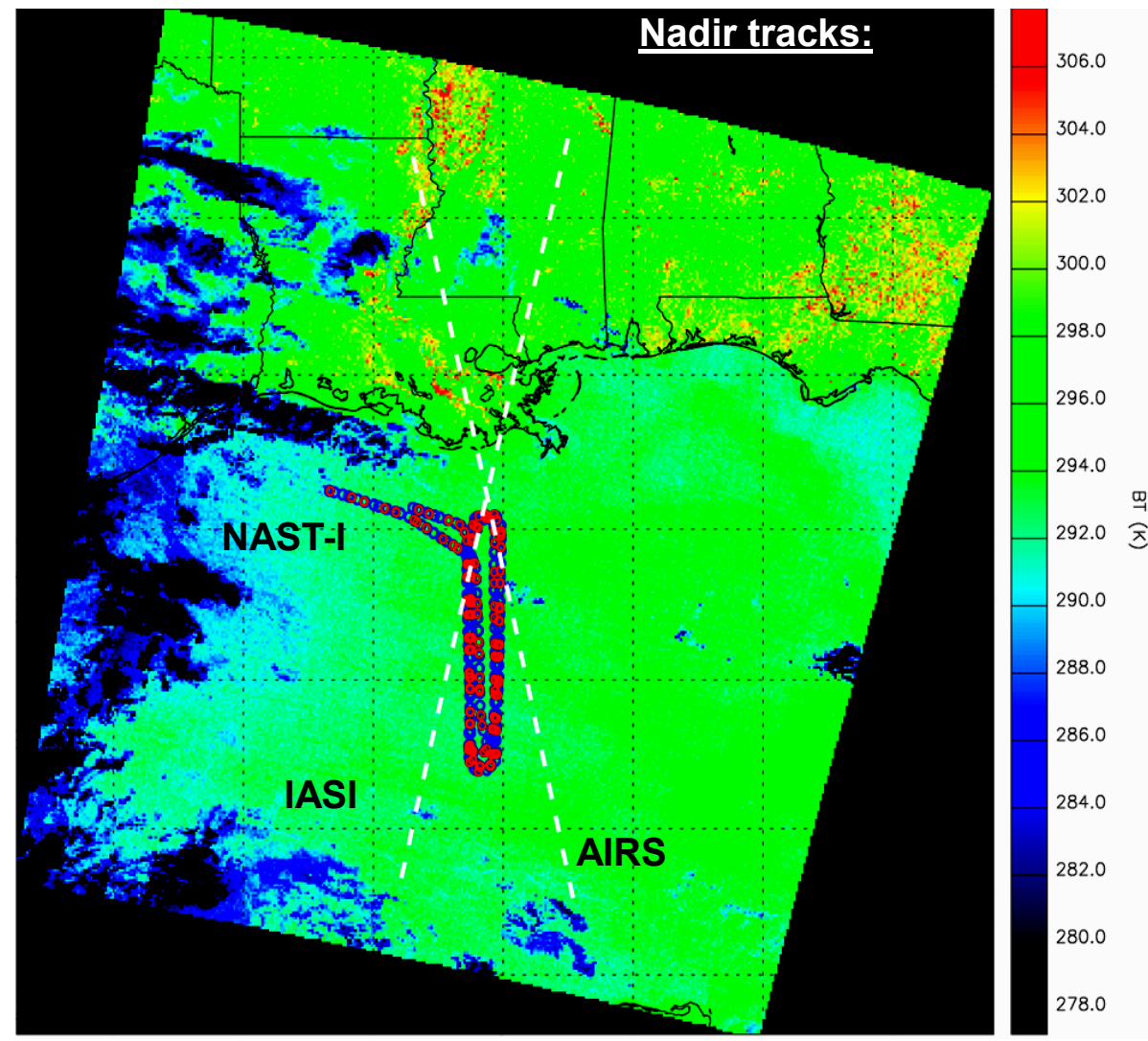

Fig. 18. Nadir tracks of IASI, AIRS, and NAST-I superimposed over the IASI imager scene of the JAIVEx flight region.

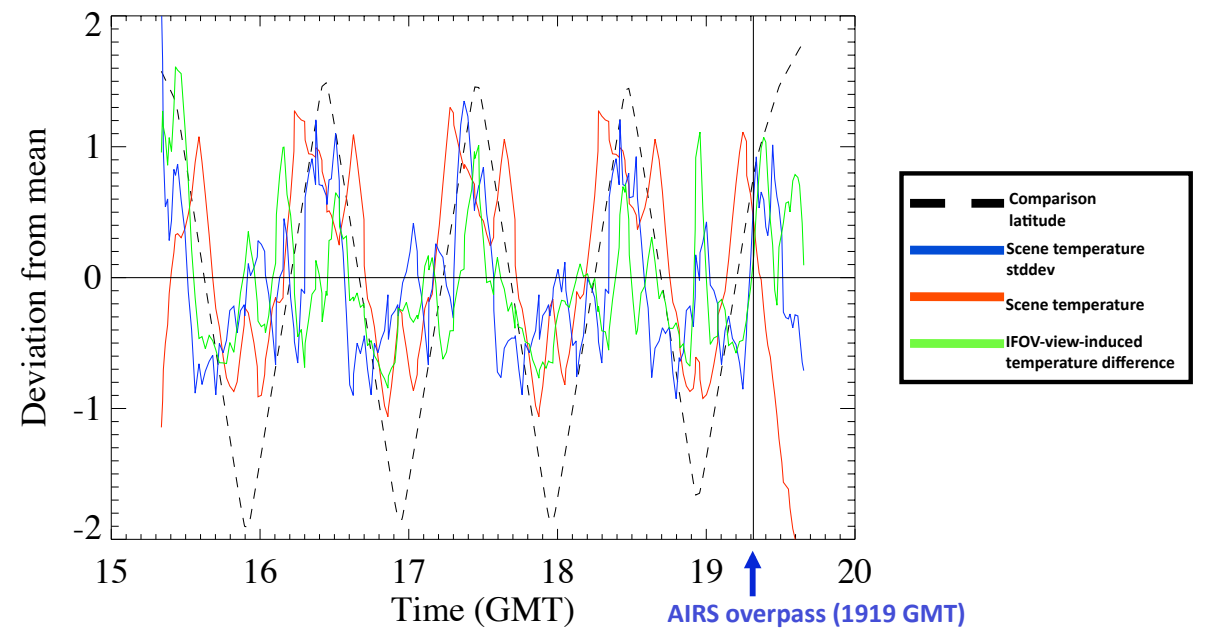

Fig. 19. Latitudinal variability of geophysical field as observed in aircraft/spacecraft measurement comparison. Sub-pixel Modis data are used to represent scene characteristics within AIRS IFOV positions and for view-induced differences relative to comparisons with NAST-I. Latitude, scene temperature and standard deviation, and IFOV-view-induced differences (i.e. between $a / c$ and $s / c$ geometries) are shown for comparison sample positions as a function of NAST-I sample time. 

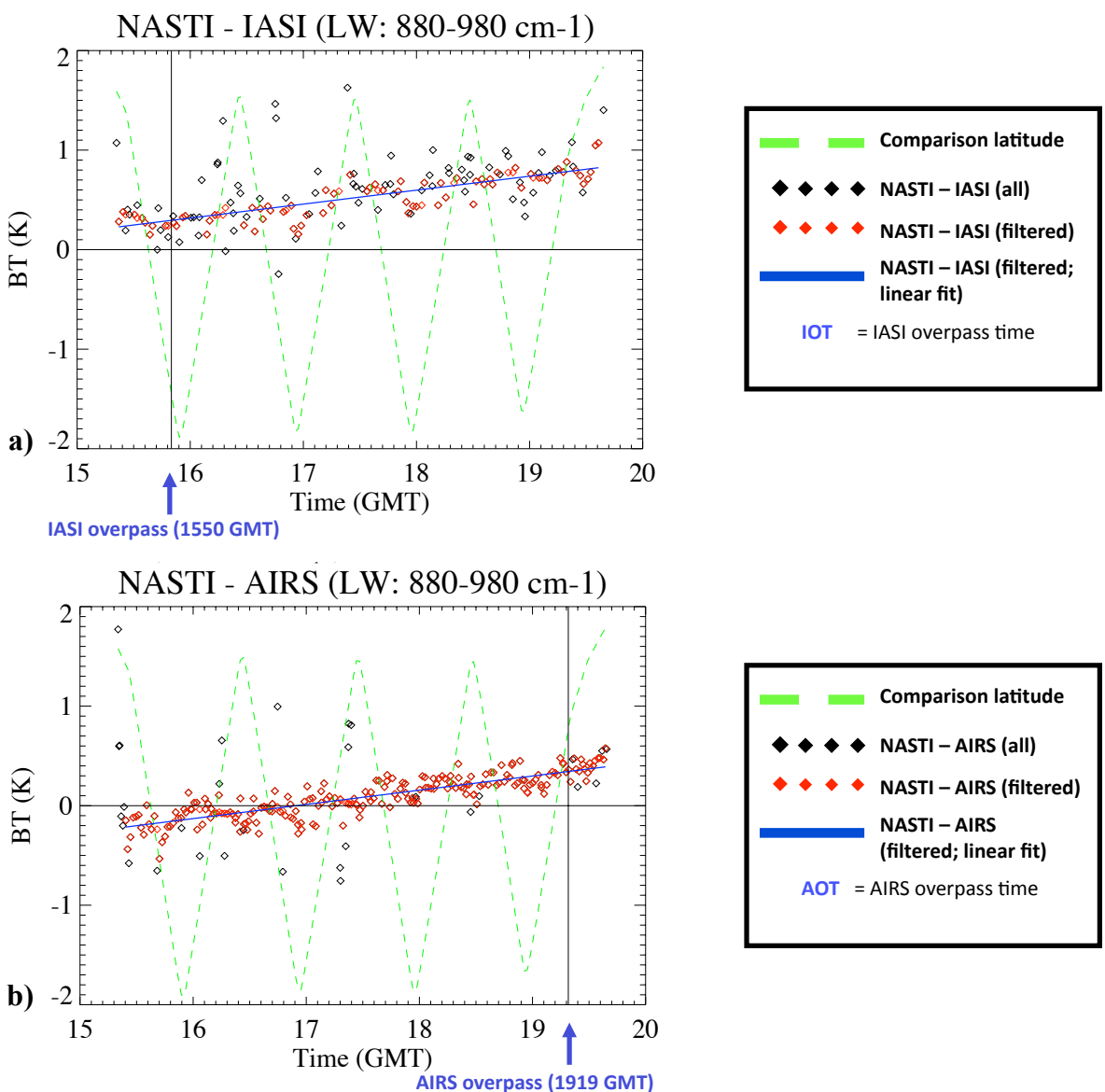

Fig. 20. Time series representation of (a) NAST-I - IASI and (b) NAST-I - AIRS for a longwave spectral interval $\left(880-980 \mathrm{~cm}^{-1}\right)$. Space coincidence is achieved for each comparison point whereas time coincidence is only achieved at satellite overpass times.

demonstrating the potential for inter-satellite cross-validation using such airborne sensors.

The next figure summarizes the sampling logistics to be used for comparing IASI versus AIRS via NAST-I. Specifically, Fig. 18 illustrates the nadir tracks of IASI, AIRS, and NAST-I superimposed over the IASI imager scene of the JAIVEx case study day flight region. Figure 19 shows the latitudinal variability of the geophysical field scene as will be observed in the aircraft/spacecraft measurement comparison. In this figure, sub-AIRS-pixel MODIS data (MB31) are used to represent scene characteristics within AIRS IFOV positions and for estimating view- and sampling-induced differences relative to subsequent comparisons with NAST-I. Time varying NAST-I spatial positions are used to achieve spatial coincidence with the AIRS/MODIS scene, albeit at the fixed-in-time AQUA overpass. A similar spatial character in field variability is also inferred using the IASI/imager scene from the Metop overpass, implying a consistent message that this type of comparison (on this case study day) will have a periodic/latitudinal oscillation superimposed due to the aircraft flight profile and relative sampling differences compared with the spacecraft sensors.
Figure 20 shows a time series representation of a) NAST-I - IASI and b) NAST-I - AIRS for a longwave spectral interval $\left(880-980 \mathrm{~cm}^{-1}\right)$. As with the last figure, space coincidence is achieved for each comparison point whereas time coincidence is only achieved at satellite overpass times. The red symbols indicate, after the filtering of outliers due to gross scene sampling differences, the time series differences of NAST-I - IASI in a) and NAST-I - AIRS in b), the blue lines represent linear fits to the red symbols, and the vertical black lines correspond to satellite overpass times as indicated. We can then calculate a residual difference between IASI and AIRS by performing a double-difference including the NAST-I observations coincident in space and time with each satellites overpass, specifically:

$\left.($ NAST-I - AIRS $)\right|_{\text {AOT }}-\left.($ NAST-I - IASI $)\right|_{\text {IOT }} \sim($ IASI - AIRS $)$,

where AOT and IOT are the AIRS and IASI overpass times, respectively. Evaluation of Eq. (1) for this case using data derived from the linear fits (blue lines) yields a difference between these spaceborne sensors of less than $0.05 \mathrm{~K}$ for this spectral interval, specifically, IASI-AIRS $=0.049 \mathrm{~K}$. Such values, lower than the NAST-I radiometric accuracy itself, 
are made possible by exploiting the stability of NAST-I accuracy, a quantity with lower uncertainty than absolute accuracy itself. Other approaches for evaluating this doubledifference, e.g. using local means or least-squares fits, have also been tried and yield similar results. It should be noted that there is also some justification for using a linear fit based upon the relationships observable in Fig. 20, i.e. aside from the sampling-induced cyclic latitudinal behavior previously discussed, the scene evolution trend is fairly linear for this longwave window spectral interval; a more sophisticated fitting approach may be necessary to adequately represent the character observed in other spectral regions (e.g. water vapor band), as is currently under investigation for future reporting. This radiometric difference between IASI and AIRS is similar to that inferred by other approaches (i.e., which reported agreement between IASI and AIRS to better than $0.1 \mathrm{~K}$ ) using SNO analysis in polar regions or NWP model fields for removing scene evolution in other regions (e.g., Strow et al., 2008; Aumann et al., 2008; and Elliott et al., 2009), however, this airborne-centric approach is not limited to application in polar regions and does not have the potential for bias by the NWP model field assimilated sensors. These examples demonstrate the utility of airborne FTS sensors, such as the NAST-I and S-HIS, to serve as reference calibration standards for enabling inter-satellite cross-validation.

\section{Summary and conclusions}

This manuscript has stressed the importance of post-launch validation activities employing airborne field campaigns to verify the quality of satellite measurement systems. Data from the JAIVEx field campaign have been shown to be very useful for IASI and AIRS validation and are serving to further refine methodologies for future advanced sounder validation associated with, for example, the Cross-track Infrared Sounder (CrIS) to fly on the NPOESS Preparatory Project (NPP) and NPOESS.

It has been demonstrated within this case study that highaltitude, airborne FTS systems such as the NAST-I and SHIS can play a vital role in assessing radiometric and spectral fidelity of spaceborne observations, since they provide a direct means of comparison with spatially- and temporallycoincident SI-traceable measurements. Comparisons with simulations are limited by knowledge of atmospheric state, surface properties, spectroscopy, and other forward model parameters, and such forward model uncertainties can easily exceed acceptable values for radiance comparisons, or that achievable using airborne sensors. Without the benefit of coincident airborne assets, attempts to do direct radiance validation through measurement-to-measurement comparisons (i.e., independent of forward radiative transfer modeling uncertainties) would be limited to intra- and inter-satellite comparisons. For this case study, direct comparisons of IASI versus AIRS correspond to comparing measurements from overpasses separated by about $3.5 \mathrm{~h}$. Even restricting comparisons to those scenes with minimum evolution, the existing scene evolution is still too large and inhibits inferring instrument differences. Intra-platform comparisons are limited to sensors collocated on same platform, so for IASI and AIRS such comparisons are restricted to those with broadband imagers having lower requirements for radiometric and spectral resolutions and calibration. While this limits their ability to validate spectral radiance stand-alone, they are still certainly very important components to and of value for validation by providing platform self-consistency verification with large sample size comparisons having negligible collocation and viewing geometry errors. Alternatively, airborne FTS versus spacecraft sensor comparisons have shown IASI and AIRS spectral radiances both matching coincident NAST-I observations to within $\sim 0.1 \mathrm{~K}$ (band-averaged). Such inter-comparisons show that IASI and AIRS have exceeded their originally-specified requirements for radiometric accuracy (i.e., a few tenths of degrees K), and demonstrate utility of the airborne FTS inter-comparison methodology employed herein for direct radiance comparisons; radiometric consistency to such levels is hard to achieve using other approaches. The airborne FTS measurements coincident with multiple satellite platforms have also been shown to have potential for serving as calibration reference standards for enabling cross-validation, as coincident NAST-I observations have demonstrated longwave band differences between IASI and AIRS on the order of less than $0.05 \mathrm{~K}$. These results exemplify the utility of aircraft under-flights for multiple satellites during multiple field campaigns toward enabling long-term monitoring of system performance and inter-satellite cross-validation.

The case study examined herein can be analyzed in further detail, bringing in more independent measurements from the other in-situ and remote sensors that also participated in the JAIVEx field campaign. Further examination of data from other flight days not presented herein will also be part of this continued analysis. To properly extrapolate results to larger temporal and spatial scales requires some measure or assumption regarding satellite sensor radiometric stability beyond that observable during a single field campaign domain. This can be accomplished through increasing the diversity of such inter-comparisons by including data from more campaigns and incorporating data from other measurement and model systems (e.g. numerical weather prediction, NWP, analysis fields); this approach can exploit the long time series and global overlap of model fields and other coincident satellite observations while utilizing how all systems intercompare with the aircraft sensor reference measurements obtained within the less-extensive field campaign observations.

Acknowledgements. The authors wish to acknowledge the NASA Langley Research Center, NASA SMD, NPOESS Integrated Program Office, and the various team members and their respective institutions for their continued, enabling support of the NAST 
program. The authors greatly appreciate the contributions from members of the NAST instrument and JAIVEx field campaign teams for making JAIVEx and this work possible. The FAAM is jointly funded by the UK Met Office and the Natural Environment Research Council. IASI has been developed and built under the responsibility of the Centre National dEtudes Spatiales (CNES). It is flown onboard the Metop satellites as part of the EUMETSAT Polar System. The IASI L1 data are received through the Unified Meteorological Archival and Retrieval Facility (UMARF) of EUMETSAT.

Edited by: A. Richter

\section{References}

Amato, U., V. Cuomo, and C. Serio: Assessing the impact of radiometric noise on IASI performances, Int. J. Remote Sens., 16(15), 2927-2938, 1995.

Aumann, H. H., Chahine, M. T. Gautier, C., Goldberg, M. D., Kalnay, E., McMillin, L. M., Revercomb, H., Rosenkranz, P. W., Smith, W. L., Staelin, D. H., Strow, L., and Susskind, J.: AIRS/AMSU/HSB on the AQUA mission: design, science objective, data products, and processing systems, IEEE T. Geosci. Remote Sens., 41, 253-264, 2003.

Aumann, H. H. and T. S. Pagano: Using AIRS and IASI data to evaluate absolute radiometric accuracy and stability for climate applications, Proc. SPIE 7085, 708504, doi:10.1117/12.795225, 2008.

Blumstein, D., Chalon, G., Carlier, T., Buil, C., Hebert, P., Maciaszek, T., Ponce, G., and Phulpin, T.: IASI instrument: technical overview and measured performances, Proc. SPIE, 5543, 196207, 2004

Cao, C., Weng, F., Goldberg, M., Wu, X., Xu, H., and Ciren, P.: Intersatellite calibration of polar-orbiting radiometers using the SNO/SCO method, Geoscience and Remote Sensing Symposium, IGARSS Proceedings, 2005 IEEE International, 1, 109112, doi:10.1109/IGARSS.2005.1526116, 2005.

Carissimo, A., Grieco, G., Serio, C., Cuomo, V., Masiello, G., and Smith, W. L.: Application of s-IASI to NAST-I, Proceedings of the International Radiation Symposium, IRS 2004: Current Problems in Atmospheric Radiation, edited by: Fischer, $\mathrm{H}$. and Sohn, B., A. Deepak publishing, ISBN: 978-0-937194-48-5, 247-250, 2006.

Cayla, F.: IASI infrared interferometer for operations and research, High Spectral Resolution Infrared Remote Sensing for Earths Weather and Climate Studies, NATO ASI Series 1, edited by: Chedin, A., Chaine, M., and N. Scott, 1993.

Chahine, C., Pagano, T. S., Aumann, H. H., Atlas, R., Barnet, C., Blaisdell, J., Chen, L., Divakarla, M., Fetzer, E. J., Goldberg, M., Gautier, C., Granger, S., Hannon, S., Irion, F. W., Kakar, R., Kalnay, E., Lambrigtsen, B. H., Lee, S.-Y., Le Marshall, J., McMillan, W. W., McMillin, L., Olsen, E. T., Revercomb, H., Rosenkranz, P., Smith, W. L., Staelin, D., Strow, L. L., Susskind, J., Tobin, D., Wolf, W., and Zhou, L.: AIRS: improving weather forecasting and providing new insights into climate, B. Am. Meteorol. Soc., 87, 911-926, 2006.

Chalon, G., Cayla, F., and Diebel, D.: IASI: An Advanced Sounder for Operational Meteorology, Proceedings of the 52nd Congress of IAF, Toulouse, France, 1-5 October 2001.
Clough, S. A., Shephard, M. W., Mlawer, E. J., Delamere, J. S., Iacono, M. J., Cady-Pereira, K., Boukabara, S., and Brown, P. D.: Atmospheric $r$ adiative transfer modeling: a summary of the AER codes, Short Communication, J. Quant. Spectrosc. Rad., 91, 233-244, 2005.

Cousins, D. and Smith, W. L.: National Polar-Orbiting Operational Environmental Satellite System (NPOESS) Airborne Sounder Testbed-Interferometer (NAST-I), Proc. SPIE, 3127, 323-331, 1997.

Elliott, D. A., Aumann, H. H., Strow, L. L., and Hannon, S. E.: Two-year comparison of radiances from the Atmospheric Infrared Sounder (AIRS) and the Infrared Atmospheric Sounding Interferometer (IASI), Proc. SPIE 7456, 74560S, DOI:10.1117/12.826996, 2009.

Gazarik, M., Candell, L., Leonard, E., and Prutzer, S.: NPOESS airborne sounder testbed interferometer (NAST-I) signal processing and initial flight test results, Proc. SPIE, Earth Observing Systems-III, 3439, 503-514, 1998.

Gibson, J. K., Kållberg, P., Uppala, S., Hernandez, A., Nomura, A., and Serrano, E.: ERA Description. Re-Analysis (ERA) Project Report Series 1, ECMWF, Shinfield Park, Reading, July 1997.

Grieco, G., Masiello, G., Matricardi, M., Serio, C., Summa, D., and Cuomo, V.: Demonstration and validation of the s-IASI inversion scheme with NAST-I data, Q. J. Roy. Meteorol. Soc., 133(S3), 217-232, 2007.

Illingworth, S. M., Remedios, J. J., and Parker, R. J.: Intercomparison of integrated IASI and AATSR calibrated radiances, Atmos. Chem. Phys., 9, 6677-6683, 2009, http://www.atmos-chem-phys.net/9/6677/2009/.

Krueger, A. J. and Minzner, R. A.: A Mid-Latitude Ozone Model for the 1976 U.S. Standard Atmosphere, J. Geophys. Res., 81(24), 4477-4481, 1976.

Larar, A. M., Smith, W. L., Zhou, D. K., and Mango, S.: Validation Studies Using NAST-I Measurements From Recent Field Campaigns, Proc. SPIE, Optical Spectroscopic Techniques and Instrumentation for Atmospheric and Space Research V, 5157, 23-33, 2003.

Larar, A. M., Smith, W. L., Zhou, D. K., Liu, X., Revercomb, H., Knuteson, R., and Mango, S.: Infrared Radiance Validation Using Aircraft- and Satellite-based Sensor systems, Proceedings of IRS 2004: Current Problems in Atmospheric Radiation, A. Deepak Publishing, Hampton, Virginia, USA, 2005.

Larar, A. M., Zhou, D. K., Liu, X., and Smith, W. L.: Select Methodology for Validating Advanced Satellite Measurement Systems, Proceedings of the International Radiation Symposium (IRS2008), Foz do Iguaçu, Brazil, 3-8 August, 2008.

Liu, X., Zhou, D. K., Larar, A. M., Smith Sr., W. L., and Mango, S. A.: Case-study of a principal-component-based radiative transfer forward model and retrieval algorithm using EAQUATE data, Q. J. Roy. Meteorol. Soc., 133(S3), 243-256, 2007.

Liu, X., Zhou, D. K., Larar, A. M., Smith, W. L., Schluessel, P., Newman, S. M., Taylor, J. P., and Wu, W.: Retrieval of atmospheric profiles and cloud properties from IASI spectra using super-channels, Atmos. Chem. Phys. Discuss., 9, 8683-8736, 2009, http://www.atmos-chem-phys-discuss.net/9/8683/2009/.

Newman, S. M., Knuteson, R. O., Zhou, D. K., Larar, A. M., Smith, W. L., and Taylor, J. P.: Radiative transfer validation study from the European Aqua Thermodynamic Experiment, Q. J. Roy. Meteorol. Soc., 135, 277-290, doi:10.1002/qj.382, 2009. 
Pagano, T. S., Aumann, H. H., Hagan, D. E., and Overoye, K.: Prelaunch and in-flight radiometric calibration of the Atmospheric Infrared Sounder (AIRS), IEEE T. Geosci. Remote, 41, 265-273, 2003.

Pagano, T. S., H. H. Aumann, R. Schindler, D. Elliott, S. Broberg, K. Overoye, and M. H. Weiler: Absolute radiometric calibration accuracy of the Atmospheric Infrared Sounder (AIRS), Proc. SPIE 7081, 70811B, doi:10.1117/12.795445, 2008.

Prutzer, S., Ryan-Howard, D. P., Garcia, J. G., and Bold, D. R.: NPOESS Airborne Sounder Testbed (NAST) IR Spectrometer Design, Proc. IEEE Aerospace Conference, Snowmass, CA, USA, 1998.

Revercomb, H., Buijs, D. L., Howell, H. B., Smith, W., and Sromovsky, L.: Radiometric calibration of IR Fourier transform spectrometers: Solution to a problem with the high-resolution interferometer sounder, Appl. Opt., 27, 32103218, 1988a.

Revercomb, H. E., LaPorte, D. D., Smith, W. L., Buijs, H., Murcray, D. G., Murcray, F. J., and Sromovsky, L. A.: High-altitude aircraft measurements of upwelling IR radiance: Prelude to FTIR from geosynchronous satellite, Mikrochim. Acta, 95, 439-444, doi:10.1007/BF01349804, 1988b.

Revercomb, H. E., Walden, V. P., Tobin, D. C., Anderson, J., Best, F. A., Ciganovich, N. C., Dedecker, R. G., Dirkx, T., Ellington, S. C., Garcia, R. K., Herbsleb, R., Knuteson, R. O., LaPorte, D., McRae, D., and Werner, M.: Recent Results From Two New Aircraft-Based Fourier-Transform Interferometers: The Scanning High-resolution Interferometer Sounder and the NPOESS Atmospheric Sounder Testbed Interferometer, ASSFTS Conference, Toulouse, France, October, 1998.

Revercomb, H. E., and Best, F. A.: Calibration of the Scanning High-resolution Interferometer Sounder (SHIS) Infrared Spectrometer: Overview (Parts 1 and 2), 2005 Calcon Workshop, Calibration of Airborne Sensor Systems, Utah State University, USA, 22 August, 2005.

Revercomb, H. E., Anderson, J. G., Best, F. A., Tobin, D. C., Knuteson, R. O., LaPorte, D. D., and Taylor, J. K.: Infrared calibration for climate: A perspective on present and future high spectral resolution instruments, Multispectral, Hyperspectral, and Ultraspectral Remote Sensing Technology, Techniques, and Applications, Gao, India, 13-16 November 2006.

Serio, C., Masiello, G., Grieco, G., Carissimo, A., Di Girolamo, P., Suma, D., Rodriguez, A., Stuhlmann, R., and Tjemkes, S.: Potential of the MTG -IRS mission to resolve small scale variability of atmospheric humidity, Proceedings of the International Radiation Symposium, IRS 2008: Current Problems in Atmospheric Radiation (IRS 2008), edited by: Nakajima, T. and Yamasoe, M., American Institute of Physics Conference Proceedings, 331-334, 2009.

Shephard, M. W.,Worden, H. M., Cady-Pereira, K. E., Lampel, M., et al.: Tropospheric Emission Spectrometer nadir spectral radiance comparisons, J. Geophys. Res., 113, D15S05, doi:10.1029/2007JD008856, 2008.

Shephard, M. W., Clough, S. A., Payne, V. H., Smith, W. L., Kireev, S., and Cady-Pereira, K. E.: Performance of the line-by-line radiative transfer model (LBLRTM) for temperature and species retrievals: IASI case studies from JAIVEx, Atmos. Chem. Phys.., 9, 7397-7417, 2009.

Simeoni, D.: IASI: A Review of Instrument Performance and Characterizations, The Centre National d'Etudes Spatiales (CNES) and EUMETSAT IASI Conference, Anglet, France, 13-16 November, 2007.

Smith, W., Larar, A., Zhou, D., Sisko, C., Li, J., Huang, B., Howell, H., Revercomb, H., Cousins, D., Gazarik, M., Mooney, D., and Mango, S.: NAST-I: Results from Revolutionary Aircraft Sounding Spectrometer, Proceedings from the SPIE Optical Spectroscopic Techniques and Instrumentation for Atmospheric and Space Research III, Conference, Denver, CO, USA, 3756, 1999.

Smith, W., Larar, A., Taylor, J., Revercomb, H., Kireev, S., Zhou, D., Liu, X., Tobin, D., Newman, S., Schlüssel, P., Clough, A., Mango, S., and St. Germain, K.: Joint Airborne IASI Validation Experiment (JAIVEx) - An overview, Proc. Int. ATOVS Study Conf. XVI, Angra dos Reis, Brazil, CIMSS, University of Wisconsin-Madison, Angra dos Reis, Brazil, 7-13 May, 2008.

Strow, L. L., Hannon, S. E., De-Souza Machado, S., Motteler, H. E., and Tobin, D. C.: Validation of the Atmospheric Infrared Sounder radiative transfer algorithm, J. Geophys. Res. 111, D09S06, doi:10.1029/2005JD006146, 2006.

Strow, L. L., Hannon, S., and Tobin, D.: IASI and AIRS validation and intercomparisons with SARTA, Advanced High Spectral Resolution Infrared Observations Workshop, EUMETSAT, Darmstadt, Germany, 15-17 September, 2008.

Taylor, J. P., Smith, W. L., Cuomo, V., Larar, A. M., Zhou, D. K., Serio, C., Maestri, T., Rizzi, R., Newman, S., Antonelli, P., Mango, S., Di Girolamo, P., Esposito, F., Grieco, G., Summa, D., Restieri, R., Masiello, G., Romano, F., Pappalardo, G., Pavese, G., Mona, L., Amodeo, A., and Pisani, G.: EAQUATE - An international experiment for hyper-spectral atmospheric sounding validation, B. Am. Meteorol. Soc., 89(2), 203-218, 2008.

Tobin, D. C., Revercomb, H. E., Knuteson, R. O., Best, F. A., Smith, W. L., Ciganovich, N. N., Dedecker, R. G., Dutcher, S., Ellington, S. D., Garcia, R. K., Howell, H. B., LaPorte, D. D., Mango, S. A., Pagano, T. S., Taylor, J. K.,van Delst, P., Vinson, K. H., and Werner, M. W.: Radiometric and spectral validation of Atmospheric Inf rared Sounder observations with the aircraft-based Scanning High-Resolution Interferometer Sounder, J. Geophys. Res., 111, D09S02, doi:10.1029/2005JD006094, 2006.

Xiong, X. and Barnes, W.: An overview of MODIS radiometric calibration and characterization, Adv. Atmos. Sci., 23(1), 69-79, 2006.

Zhou, D. K., Smith, W. L., Li, J., Howell, H. B., Cantwell, G. W., Larar, A. M., Knuteson, R. O., Tobin, D. C., Revercomb, H. E., and Mango, S. A.: Thermodynamic product retrieval methodology for NAST-I and validation, Appl. Optics, 41, 6957-6967, 2002.

Zhou, D. K., Smith, W. L., Liu, X., Larar, A. M., Huang, H.-L. A., Li, J., McGill, M. J., and Mango, S. A.: Thermodynamic and cloud parameters retrieval using infrared spectral data, Geophys. Res. Lett., 32, L15805, doi:10.1029/2005GL023211, 2005.

Zhou, D. K., Smith, W. L., Cuomo, V., Taylor, J. P., Barnet, C. D., Di Girolamo, P., Pappalardo, G., Larar, A. M., Liu, X., Newman, S. M., Lee, C., and Mango, S. A.: Retrieval validation during the European Aqua Thermodynamic Experiment, Q. J. Roy. Meteorol. Soc., 133, 203-215, 2007a.

Zhou, D. K., Smith Sr., W. L., Liu, X., Larar, A. M., Mango, S. A., and Huang, H.-L.: Physically retrieving cloud and thermodynamic parameters from ultraspectr al IR measurements, J. Atmos. Sci., 64, 969-982, $2007 b$. 
Zhou, D. K., Smith, W. L., Larar, A. M., Liu, X., Taylor, J. P., Schlüssel, P., Strow, L. L., and Mango, S. A.: All weather IASI single field-of-view retrievals: case study - validation with JAIVEx data, Atmos. Chem. Phys., 9, 2241-2255, 2009,

http://www.atmos-chem-phys.net/9/2241/2009/. 